Article

\title{
Swimming Behavior of Downstream Moving Fish at Innovative Curved-Bar Rack Bypass Systems for Fish Protection at Water Intakes
}

\author{
Claudia Beck $\left.{ }^{1,2}, * \mathbb{(}\right)$, Ismail Albayrak ${ }^{2}\left(\mathbb{D}\right.$, Julian Meister ${ }^{2}{ }^{\circ}$, Armin Peter $^{3}$, Oliver M. Selz ${ }^{4}$, \\ Claudia Leuch ${ }^{2}$, David F. Vetsch ${ }^{2} \mathbb{D}$ and Robert M. Boes ${ }^{2}$ (D) \\ 1 IUB Engineering AG, 3007 Bern, Switzerland \\ 2 Laboratory of Hydraulics, Hydrology and Glaciology (VAW), ETH Zurich, 8093 Zurich, Switzerland; \\ albayrak@vaw.baug.ethz.ch (I.A.); meister@vaw.baug.ethz.ch (J.M.); leuch@vaw.baug.ethz.ch (C.L.); \\ vetsch@vaw.baug.ethz.ch (D.F.V.); boes@vaw.baug.ethz.ch (R.M.B.) \\ 3 FishConsulting GmbH, 4600 Olten, Switzerland; apeter@fishconsulting.ch \\ 4 Department of Fish Ecology and Evolution, Centre of Ecology, Evolution and Biogeochemistry, \\ EAWAG Swiss Federal Institute of Aquatic Science and Technology, 6047 Kastanienbaum, Switzerland; \\ Oliver.Selz@eawag.ch \\ * Correspondence: claudia.beck@iub-ag.ch
}

Received: 1 October 2020; Accepted: 10 November 2020; Published: 19 November 2020

\begin{abstract}
New types of fish guidance structures with vertical curved bars and a subsequent bypass system represent a promising technical solution for the protection and guidance of downstream moving fish at run-of-river hydropower plants and water intakes. These so-called "curved-bar rack bypass systems" (CBR-BSs) function as a mechanical behavioral barrier and are characterized by low hydraulic losses, a symmetrical downstream flow field and an overall high fish guidance efficiency in the laboratory for a wide array of European freshwater fish species. This paper presents the results of the hydraulic and live-fish laboratory tests of an optimized CBR-BS configuration with a bar spacing of $50 \mathrm{~mm}$ and $30^{\circ}$ rack angle to the flow direction. The tests were conducted with six different fish species in an ethohydraulic laboratory flume at different approach flows $(0.5 \mathrm{~m} / \mathrm{s}, 0.7 \mathrm{~m} / \mathrm{s})$ and different bypass entrance velocities $(0.6-1.0 \mathrm{~m} / \mathrm{s})$. A numerical model was used to simulate the flow fields in the CBR-BS in order to link the fish behavior to the hydrodynamic cues created by the CBR-BS. Lower approach flow velocities decreased the hydraulic cues of the CBR, which led to more rack passages. A $20 \%$ velocity increase towards the bypass entrance significantly increased the fish guidance efficiency compared to a $40 \%$ velocity increase. The tested CBR-BS resulted in overall higher interspecies fish protection and guidance efficiencies compared to the more commonly applied horizontal-bar rack with a narrow bar spacing of $20 \mathrm{~mm}$. Recommendations for a sustainable and cost-effective application of CBR-BSs are given.
\end{abstract}

Keywords: downstream fish migration; movement ecology; fish guidance structure; fish passage; fish protection; fish behavior; curved-bar rack; bypass system; ethohydraulics

\section{Introduction}

\subsection{Fish Guidance Structures}

During downstream movements, fish can be delayed and are subjected to injury or mortality when passing turbines, spillways or bypasses at run-of-river hydropower plants (HPPs), resulting in cumulative negative impacts such as the reduction of fish population size, species distributions and extinctions. Fish guidance structures (FGSs) with an adjacent bypass system (BS) can protect 
downstream moving fish from hydropower and water intakes, guide them and transport them downstream without harm.

FGSs are typically placed in front of a power or water intake at a horizontal rack angle of $\alpha=10^{\circ}-45^{\circ}$ to the approach flow direction and can be divided into FGSs with narrow bar spacings functioning as physical barriers, and those with wider bar spacings functioning as mechanical behavioral barriers. The former keep fish from turbine entrainment with clear bar spacings $s_{b}=10-30 \mathrm{~mm}$ based on the size of the target fish species and operational aspects. The angled physical barriers with horizontally aligned bars, termed horizontal-bar racks (HBRs) are widely used and approved by authorities, and have to date been mainly applied at HPPs in Austria, Germany, Sweden and Switzerland [1,2].

Mechanical behavioral FGSs, i.e., louvers, angled-bar racks or modified angled-bar racks (MBRs), consist of vertical bars placed at a flow attack angle of $\beta=45^{\circ}-90^{\circ}$ [3-7]. The operating principle of these FGSs with clear bar spacings of $s_{b}=25-100 \mathrm{~mm}$ is to guide fish to the bypass with hydrodynamic cues created by the bars instead of physically blocking fish from a water intake. When approaching the structure, fish should be able to perceive the high pressure and velocity gradients around and between the bars, resulting in avoidance behaviors. The velocity component parallel to the rack guides the fish towards the bypass. Current designs of these FGSs consist of bars with a straight cross section (Figure 1a,b). Since these designs lead to high head losses and an asymmetrical flow field downstream of the rack, novel curved bar shapes were developed by Beck [5] and Beck et al. [8,9] (Figure 1c). Curved bars have an inflow angle of $\beta=45^{\circ}-90^{\circ}$ and an outflow angle of $\delta=0^{\circ}$, i.e., parallel to the downstream channel walls (Figure 1c).

(a)

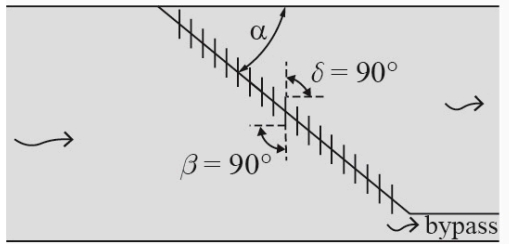

(b)

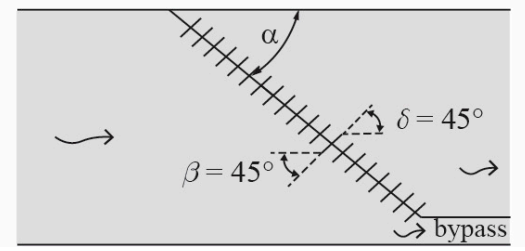

(c)

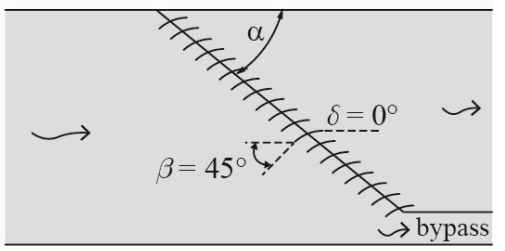

Figure 1. Schematic illustration (top view) of mechanical behavioral barriers: (a) louver, (b) modified angled-bar rack (MBR), (c) curved-bar rack (CBR), all with vertical bars and an adjacent bypass system (BS).

Beck et al. [8,9] reported that the hydraulic head losses of CBRs are on average 4.2 times lower than those of MBRs. The recommended CBR configuration with $\alpha=30^{\circ}, \beta=45^{\circ}$ and $s_{b}=50 \mathrm{~mm}$ resulted in a head loss coefficient of $\xi_{R}=0.57$, which is in the lower range of typical $\xi_{R}$ values for conventional intake trash racks [8]. Furthermore, the curved bars promote a flow-straightening effect, leading to a gradual velocity increase towards the bypass and a symmetrical downstream flow field, which are favorable for fish guidance and turbine operation, respectively [9].

\subsection{Fish Swimming Behavior, Fish Guidance Parameters and Fish Guidance Efficiency}

Despite the increasing number of ethohydraulic and field studies on fish downstream movement, the knowledge on the behavior of different fish species and life stages when encountering a barrier is highly incomplete. Most studies have focused on specific life stages of a few species. The main factors that have been determined to result in fish behavioral responses to FGS-BSs are accelerating, decelerating or turbulent flow. However, studies on the swimming behavior in accelerating or decelerating flows mostly focus on salmonid or catadromous species [6,10-12], whereas the knowledge on the swimming behavior of cyprinid species is limited. Fish are able to perceive spatial velocity gradients $(S V G)$ due to the induced pressure difference inside the canals and pores of their lateral line organ. Enders et al. [12] found that Chinook salmon (Oncorhynchus tshawytscha) smolts preferred streamwise spatial velocity gradients of $S V G_{x}=\partial U / \partial x \leq 1.0-1.2 \mathrm{~s}^{-1}$, with $U=$ streamwise velocity component. Similar threshold values might be applicable for other fish species. Haro et al. [10] further 
observed that Atlantic salmon (Salmo salar) smolts avoided velocities higher than $1 \mathrm{~m} / \mathrm{s}$ with burst swimming. A reduction of the flow velocity just in front of or inside a bypass can cause confusion and trigger hesitation of fish [3,6]. Some authors therefore propose a velocity increase rate as a bypass design parameter expressed by the ratio of bypass entrance velocity to mean approach flow velocity $V R=U_{b y, i n} / U_{o}[11,13,14]$. Ducharme [11] determined the highest louver bypass system guidance and acceptance rates for $V R \geq 1.5$ in a field study with Atlantic salmon, which are strong swimmers. The United States Bureau of Reclamation (USBR) [13] gives a general design value of $V R=1.1-1.5$ for louver bypass systems for all fish species, while Ebel [1] recommends $V R=1.0-2.0$ for horizontal-bar rack bypass systems (HBR-BSs).

Different velocity components of the flow field upstream of the rack can be used to derive fish guidance parameters for FGSs. Courret and Larinier [15] introduced the ratio of the parallel to the normal velocity component $V_{p} / V_{n}$ as the fish guidance capacity (FGC) and proposed $V_{p} / V_{n}>1$ for a high fish guidance efficiency. To ensure that fish can swim actively along the FGS without exhaustion, the normal velocity component at the FGS should be smaller than the sustained swimming speed of fish, i.e., $V_{n}<v_{\text {sustained }}[1,16]$.

The fish guidance efficiency (FGE) of louvers was first investigated in a field study by Bates and Vinsonhaler [6]. They reported the highest FGE ranging from 90\%-99\% for Chinook salmon, steelhead trout (Oncorhynchus mykiss), striped bass (Morone saxatilis) and American shad (Alosa sapidissima) at a louver with $s_{b}=50 \mathrm{~mm}$ and $10^{\circ} \leq \alpha \leq 16^{\circ}$. Ruggles and Ryan [14] studied the FGE of floating louvers with $\alpha=11.2^{\circ}$ and $s_{b}=60 \mathrm{~mm}$ for the guidance of surface-oriented fish. They reported an FGE of $50 \%$ and $87 \%$ for Chinook salmon fry and steelhead trout smolts, respectively. Ducharme [11] investigated the FGE of Atlantic salmon smolts at a V-shaped louver with $\alpha=12^{\circ}$ and $s_{b}=50 \mathrm{~mm}$ installed in a canal. The FGE increased from $57 \%-80 \%$ after the bypass was modified to increase bypass flow velocities and reduce turbulence.

The Electric Power Research Institute (EPRI) and Dominion Millstone Laboratories (DML) [17] investigated the FGE of louvers and angled-bar racks with $\alpha=15^{\circ}$ and $45^{\circ}$ with American eel (Anguilla rostrata) and seven riverine freshwater fish species from hatcheries in a laboratory study. They reported FGEs $>70 \%$ for a louver with $\alpha=15^{\circ}$ and a $0.3 \mathrm{~m}$ high bottom overlay (corresponding to $17 \%$ of the approach flow depth $h_{0}$ ) at approach flow velocities of $0.3-0.9 \mathrm{~m} / \mathrm{s}$. The application of the bottom overlay at louvers and angled-bar racks led to an FGE increase of $21 \%$ and $13 \%$, respectively. The authors concluded that louvers and angled-bar racks with $\alpha=45^{\circ}$ did not achieve satisfactory results regarding neither the FGE nor the hydraulic performance due to high head losses and, hence, recommended FGSs with $\alpha=15^{\circ}$ as they present a high potential for fish guidance at HPPs.

Kriewitz [18] and Albayrak et al. [3] conducted hydraulic and live-fish experiments in the laboratory with five European freshwater fish species, namely common barbel (Barbus barbus), spirlin (Alburnoides bipunctatus), European grayling (Thymallus thymallus), brown trout (Salmo trutta) and European eel (Anguilla anguilla), investigating the FGE of louvers and MBRs with two different bar spacings. They found that clear bar spacings $s_{b}=110 \mathrm{~mm}$ had significantly lower FGEs than $s_{b}=50 \mathrm{~mm}$, whereas the approach flow velocity did not show a significant impact on the FGE in the tested range of $0.3-0.8 \mathrm{~m} / \mathrm{s}$. The tested louver with $\alpha=15^{\circ}$ and $s_{b}=50 \mathrm{~mm}$ resulted in high transverse flow velocities and water surface fluctuations at the downstream $(d / s)$ rack end, and a strong velocity decrease at the bypass entrance. As a result, fish avoided these areas entirely and hesitated or shied back from the bypass entrance, leading to a higher rack passage rate and an overall low FGE. Due to the improved flow conditions, MBRs led to significantly higher FGEs than louvers. Their live-fish tests resulted in an interspecies average FGE of MBRs with $\alpha=15^{\circ}$ and $30^{\circ}$ of $80 \%$ and $65 \%$, respectively. The use of a bottom overlay with an overlay height of $h_{B o}=0.11 \cdot h_{0}$ significantly increased the interspecies average FGE to more than $90 \%$ for both MBR configurations independent of the rack angle $\alpha\left(15^{\circ}\right.$ or $\left.30^{\circ}\right)$.

CBRs are expected to result in similar or higher FGEs due to the improved upstream flow fields compared to equivalent MBR configurations [9]. However, to the best of our knowledge, no study exists on the FGE of CBRs. Therefore, the present study aims to evaluate the hydraulic and fish 
biological performance of a CBR-BS under different hydraulic conditions and for various European fish species. To this end, the following objectives were set for the present study: (I) quantification of flow fields around a CBR-BS using a numerical model for different approach flow and bypass velocities, (II) assessment of the fish protection and fish guidance efficiencies of a CBR-BS under controlled laboratory conditions for selected European fish species with a diverse migration behavior, namely spirlin, common barbel, nase (Chondrostoma nasus), European eel, Atlantic salmon parr and brown trout and (III) link the hydrodynamic cues of the CBR-BS to the observed fish swimming behavior. The resulting fish protection and guidance efficiencies are compared with those of the more commonly applied HBR-BS. The live-fish tests with the HBR-BS were conducted by Meister [2] in the same time period with the same fish and the same flume setup. Furthermore, based on the present findings, recommendations for a sustainable and cost-effective application of CBR-BSs are provided.

\section{Materials and Methods}

\subsection{Ethohydraulic Flume}

The ethohydraulic tests were conducted in a $30 \mathrm{~m}$ long, $1.50 \mathrm{~m}$ wide and $1.20 \mathrm{~m}$ deep open channel laboratory flume with a horizontal concrete bed (Figure $2 a, b)$. In the test section upstream of the rack and at the bypass entrance, the side wall of the flume was equipped with glass for lateral observation. The flume was connected to a closed water circuit with a cooling system. At the flume inlet, a diffuser and honeycomb-shaped flow straighteners ensured symmetrical inflow conditions, and surface waves were suppressed with hard foam floats (Figure $2 b$ ). The 1:1 scaled section model of the hydraulically optimized CBR configuration with $\alpha=30^{\circ}, \beta=45^{\circ}, s_{b}=50 \mathrm{~mm}$ (Figure 2c) $[5,8,9]$ was placed in the flume center with an adjacent full-depth open channel bypass. The rack covered the downstream flume width of $w_{d s}=1.15 \mathrm{~m}$ with a resulting rack length of $l_{R}=2.3 \mathrm{~m}$ (Figure 3 ). The bypass channel was separated from the downstream channel by a $0.1 \mathrm{~m}$ thick brick wall, resulting in a bypass width of $w_{b y}=0.25 \mathrm{~m}$. A curved hard foam wedge was placed between the $\mathrm{d} / \mathrm{s}$ rack end and the brick wall to ensure a gradual flow transition from the rack into the bypass. The discharge in the downstream and in the bypass channel was controlled separately with a flap gate at the end of each channel.

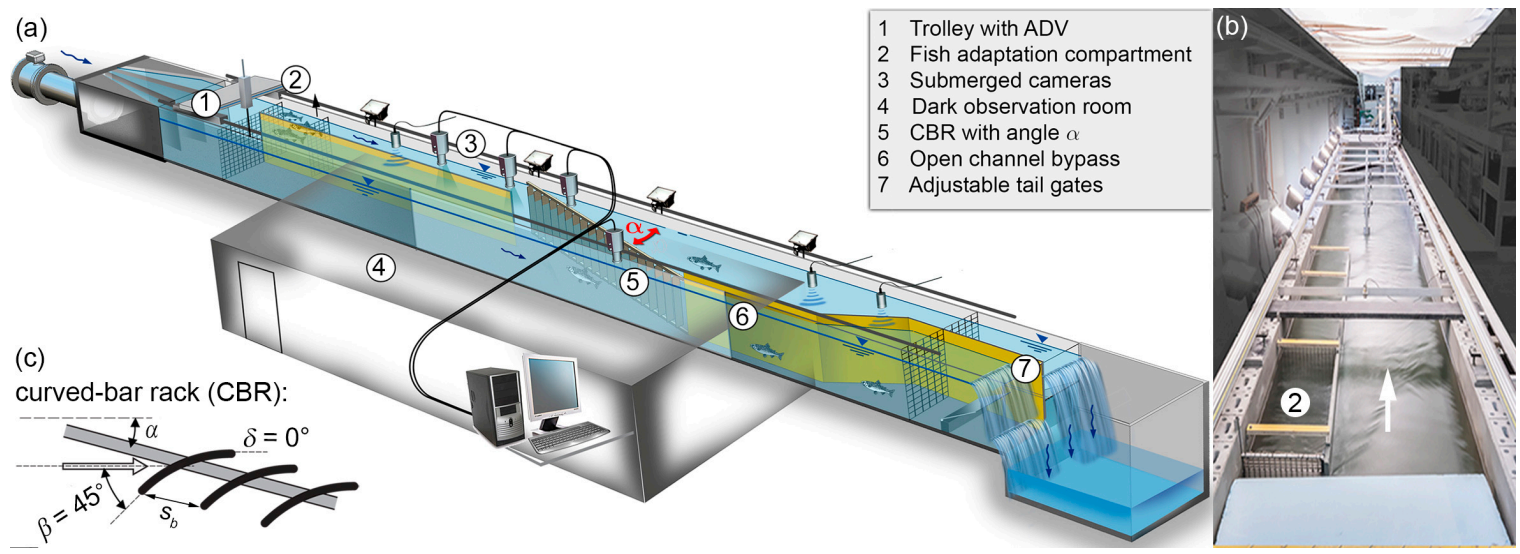

Figure 2. (a) Schematic 3D view and (b) photo of the ethohydraulic model flume, and (c) CBR definition sketch; adapted from [5]. 


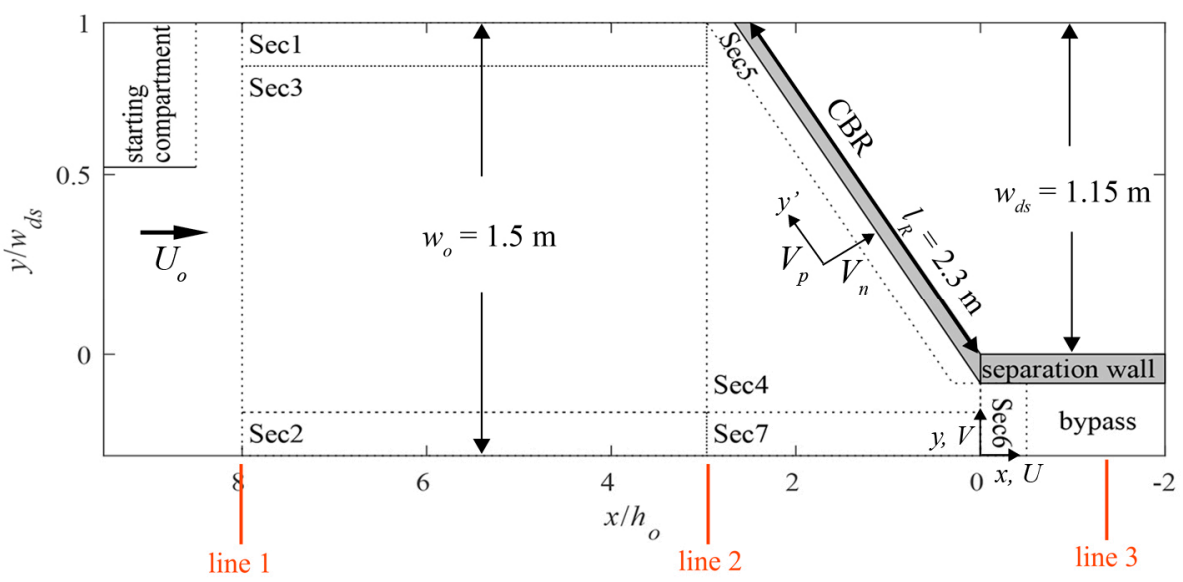

Figure 3. Definition of sectors Sec1-Sec7 for the data analysis of fish swimming behavior.

\subsection{Live-Fish Tests}

The live-fish tests were conducted with a permit from the veterinary office of Zurich in two phases according to specific periods of downstream movement for some fish species. The tests with spirlin, common barbel, nase and European eel were conducted in autumn 2018. Those with Atlantic salmon parr and brown trout were run in spring 2019. Wild fish were caught by electrofishing (DC $7.0 \mathrm{~kW}$, Grassl EL 64_II and Grassl ELT 60-II, $1.3 \mathrm{~kW}$ ) in different Swiss Plateau rivers (Himmelbach (canton ZH), Suhre (LU), Thur and inland canal (both ZH), Möhlinbach (AG), Altbach (ZH), Mülitalbach (LU) or Murg tributary (TG)) and transferred to fish holding tanks in the laboratory for a maximum of 7 days without feeding (animal holding permit from the veterinary office of Zurich). The laboratory holding tanks were connected to a closed water circuit of the flume and a cooling system with a constant water circulation. The water temperature in the river reach, where the fish were caught, was measured and adapted accordingly in the laboratory water circuit to $12-16{ }^{\circ} \mathrm{C}$. The water quality (e.g., temperature, $\mathrm{pH}$, oxygen concentration and turbidity) in the holding tanks and the flume were recorded daily. The $\mathrm{pH}$ values were between 7 and 8 and the water was always clear. After conducting the tests, all fish were brought back to the same river reach of the source river. Transportation and handling processes were minimized as much as possible to reduce stress.

For each test run, three fish were transferred from the holding tanks to buckets with a dip net. They were photographed to measure their total length and then placed in a $1 \mathrm{~m}$ long, $0.5 \mathrm{~m}$ wide adaptation and starting compartment near the flume inlet at the left flume wall in the flow direction, i.e., opposite the wall leading to the bypass (Figures $2 \mathrm{~b}$ and 3 ). In this compartment, the fish acclimatized to the flow conditions for $15 \mathrm{~min}$ in accordance with Albayrak et al. [3]. After the acclimatization phase, the downstream fence was raised and the three fish were free to swim downstream and interact with the CBR-BS. Five synchronized high-resolution cameras slightly submerged from above simultaneously recorded the fish movements at $50 \mathrm{~Hz}$ (Figure 2a,b). The videos were later analyzed with fish-tracking software using Matlab [19]. Manual time measurements and observations were additionally recorded with a standardized protocol for each test. The duration of each test was $30 \mathrm{~min}$ after the starting compartment was opened. The fish were immediately recaptured from the flume with a dip net after each test. They were transferred back into the holding tanks and not used for another test on the same day. To reduce the total number of fish used for experimental purposes, each individual fish was used up to three times but with different hydraulic conditions, on different days and within another group of three fish.

During the live-fish tests, eight $1000 \mathrm{~W}$ lamps were positioned behind the flume and oriented towards a white linen sheet hanging over the flume for uniform illumination with a diffused light source (Figure 2b). These bright lighting conditions were chosen to motivate fish to move downstream and prevent them from hiding in darker corners. Furthermore, they enhanced the contrast for the video recording and the fish tracking. For fish species such as the European eel, which prefer darker 
conditions, the bright lighting of the flume could possibly have affected their behavior. The glass wall was covered with a perforated foil to avoid reflections. The ideal test condition for behavioral analyses would require equal numbers of replicates for all hydraulic conditions. However, it was not possible to catch enough fish of the same size range for all tests. Furthermore, only salmon parr, which did not yet show the migratory phenotype, could be caught. Although these fish might not yet be willing to move far in the river, they were actively swimming downstream in the laboratory flume.

The depth-averaged flow velocity at the bypass entrance $U_{b y, i n}$ was measured at $x / h_{0}=0$ (Figure 3). Live-fish tests were conducted for two mean approach flow velocities: (i) $U_{o}=Q_{o} /\left(w_{0} \cdot h_{o}\right)=0.5 \mathrm{~m} / \mathrm{s}$ with the average bypass velocities of $U_{b y, \text { in }}=0.6$ and $0.7 \mathrm{~m} / \mathrm{s}$, and (ii) $U_{o}=0.7 \mathrm{~m} / \mathrm{s}$ with $U_{b y, \text { in }}=0.85$ and $1.0 \mathrm{~m} / \mathrm{s}$, where $Q_{o}=$ approach flow discharge, $w_{0}=$ flume width $=1.5 \mathrm{~m}$ and $h_{0} \cdot=$ approach flow depth $=0.9 \mathrm{~m}$. The resulting bypass inflow to mean approach flow velocity ratios $(V R)$ were $V R=U_{b y, i n} / U_{o}=1.2$ and 1.4 for each approach flow condition (Table 1 ). These ratios were chosen based on the findings and recommendations in the literature $[1,12,13]$. The resulting relative bypass discharges were $Q_{b y}=0.17-0.22 \cdot Q_{o}$. For these main tests, numerical simulations were conducted (cf. Section 2.5). Note that nase, European eel and Atlantic salmon parr could not be tested with all four main hydraulic conditions due to high effort to catch large numbers of these fish. The effect of the CBR compared to the situation without a rack installed on the fish guidance efficiency (FGE) was investigated with spirlin in Test T1. The effect of a lower approach flow velocity of $U_{o}=0.3 \mathrm{~m} / \mathrm{s}$ was tested with brown trout in Test T2. A lower velocity ratio of $V R=1.1$ was tested for nase in Test T3, since these fish reacted with high avoidance to $V R=1.2$.

The minimum, mean and maximum fish total lengths $T L_{\min }, T L_{\text {mean }}$ and $T L_{\max }$, respectively, are listed in Table 1 for all live-fish tests conducted in this study. The table further lists the total number $N$ of fish per species and hydraulic conditions that were tested and the number of fish $n$ leaving the starting compartment, actively swimming downstream and interacting with the CBR-BS (crossing line 2 in Figure 3). The fish that did not cross line 2 in Figure 3 were classified as inactive and excluded from all further analyses.

Table 1. Test program for the live-fish tests with $U_{o}=$ mean approach flow velocity, $U_{b y, \text { in }}=$ mean bypass entrance velocity, $V R=$ velocity ratio $=U_{b y, i n} / U_{0}, T L=$ fish total length, $N=$ number of tested fish and $n=$ number of active fish, which were used for further analyses.

\begin{tabular}{|c|c|c|c|c|c|c|c|c|}
\hline \multirow{2}{*}{ Test } & \multirow{2}{*}{ Rack } & $U_{o}$ & $U_{b y, i n}$ & $V R$ & Fish & $T L_{\min }-T L_{\max }$ & $N$ & $n$ \\
\hline & & $(\mathrm{m} / \mathrm{s})$ & $(\mathrm{m} / \mathrm{s})$ & $(-)$ & Species & $\left(T L_{\text {mean }}\right)(\mathrm{cm})$ & $(-)$ & $(-)$ \\
\hline $\mathrm{T} 1$ & no rack & 0.50 & 0.60 & 1.2 & spirlin & $8.5-11.9(9.9)$ & 21 & 21 \\
\hline $\mathrm{T} 2$ & \multirow{18}{*}{ CBR } & 0.30 & 0.36 & 1.2 & trout & $12.1-19.9(16.2)$ & 18 & 16 \\
\hline T3 & & 0.50 & 0.55 & 1.1 & nase & $6.5-8.4(7.1)$ & 9 & 9 \\
\hline $\mathrm{T} 4$ & & \multirow{6}{*}{0.50} & \multirow{6}{*}{0.60} & \multirow{6}{*}{1.2} & spirlin & $8.6-12.5(10.0)$ & 36 & 32 \\
\hline T5 & & & & & barbel & $9.7-22.0(14.3)$ & 27 & 22 \\
\hline T6 & & & & & trout & 9.5-20.4 (13.7) & 42 & 25 \\
\hline $\mathrm{T} 7$ & & & & & salmon & $7.9-15.0(11.0)$ & 30 & 30 \\
\hline T8 & & & & & nase & $6.0-8.9(7.3)$ & 24 & 24 \\
\hline T9 & & & & & eel & $50.4-80.9(67.1)$ & 16 & 14 \\
\hline $\mathrm{T} 10$ & & \multirow{4}{*}{0.50} & \multirow{4}{*}{0.70} & \multirow{4}{*}{1.4} & spirlin & $8.6-10.8(9.8)$ & 30 & 29 \\
\hline $\mathrm{T} 11$ & & & & & barbel & 9.9-20.7 (15.3) & 24 & 23 \\
\hline $\mathrm{T} 12$ & & & & & trout & $10.6-20.2(14.8)$ & 36 & 24 \\
\hline $\mathrm{T} 13$ & & & & & salmon & $9.0-13.3(11.1)$ & 30 & 30 \\
\hline $\mathrm{T} 14$ & & \multirow{3}{*}{0.70} & \multirow{3}{*}{0.85} & \multirow{3}{*}{1.2} & spirlin & $8.4-11.8(10.0)$ & 33 & 33 \\
\hline $\mathrm{T} 15$ & & & & & barbel & $10.3-21.5(15.9)$ & 24 & 16 \\
\hline T16 & & & & & trout & $10.2-20.1(13.7)$ & 54 & 29 \\
\hline $\mathrm{T} 17$ & & \multirow{3}{*}{0.70} & \multirow{3}{*}{1.00} & \multirow{3}{*}{1.4} & spirlin & $8.4-11.9(10.0)$ & 30 & 27 \\
\hline $\mathrm{T} 18$ & & & & & barbel & $11.2-20.6(14.7)$ & 27 & 23 \\
\hline T19 & & & & & trout & 9.9-19.7 (14.4) & 39 & 23 \\
\hline
\end{tabular}




\subsection{Data Analysis}

To analyze the fish behavior in detail, the ethohydraulic flume is divided into different sectors (Figure 3). Sector 1 (Sec1) describes a $15 \mathrm{~cm}$ wide corridor along the left concrete flume wall in the flow direction, i.e., opposite the bypass location, Sector 2 (Sec2) and Sector 7 (Sec7) are $15 \mathrm{~cm}$ wide corridors along the right flume wall in front of the bypass and Sector 3 (Sec3) and 4 (Sec4) cover the flume center up- and downstream of line 2, respectively. Sector 5 (Sec5) is a $15 \mathrm{~cm}$ wide corridor parallel to and upstream of the rack and, finally, Sector 6 (Sec6) describes the first $50 \mathrm{~cm}$ inside the bypass, which are still recorded by the most downstream camera. The choice of $15 \mathrm{~cm}$ for the width of rack-parallel Sec5 is judged appropriate since the strong hydrodynamic cues of the CBR, i.e., increased pressure and velocity gradients, only extend to about $40 \mathrm{~mm}$ upstream of the rack (cf. Section 3.1).

Although three fish were tested simultaneously, each fish was counted as an individual data point. Since typical swarm fish such as nase still performed separate actions within the tested group of fish, it was assumed that the three fish tested simultaneously did not lead to pseudo-replication.

Each fish performed one of the following four possible actions during the tests:

1. Bypass passage: the fish swam downstream, did not pass through the CBR, but swam at least $1.5 \mathrm{~m}$ into the bypass (line 3 in Figure 3) ("bypassed", subscript by, all);

2. Bypass passage with rack interaction: the fish swam into Sector 5 (Sec5) during the test before finally swimming at least $1.5 \mathrm{~m}$ into the bypass ("bypassed with rack interaction", subscript by,red, since this analysis excludes fish that swam into the bypass without rack interaction and therefore reduces the number of bypass passages);

3. Rack passage: the fish swam downstream and eventually passed through the CBR ("rack passage", subscript rack);

4. Refusal: the fish swam downstream of line 2, did not pass through the rack, and also refused to swim into the bypass within $30 \mathrm{~min}$ ("refusal", subscript ref).

The distinction between all bypass passages with and without rack interaction $\left(N_{b y}\right.$,all $)$, and only bypass passages with rack interaction $\left(N_{b y}\right.$,red $)$ was made because some fish swam along the right channel wall directly into the bypass without interacting with the CBR. To assess the effect of the CBR on the fish guidance efficiency (FGE), fish that did not enter rack-parallel Sector 5 were therefore excluded from this particular analysis. Since spirlin showed an avoidance behavior further upstream of the CBR, the width of Sector 5 was increased to $30 \mathrm{~cm}$ for the assessment $N_{b y \text {,red }}$ for this fish species only (cf. Section 3.2.1).

From the above listed actions, four parameters were defined to evaluate the performance of the CBR-BS: the fish guidance efficiency (FGE) and the fish protection efficiency (FPE) of the CBR-BS including only bypass passages with rack interaction (Equations (1) and (2)), and the total system fish guidance efficiency $\left(\mathrm{FGE}^{*}\right)$ and the total system fish protection efficiency $\left(\mathrm{FPE}^{*}\right)$ including all bypass passages (Equations (3) and (4)):

$$
\begin{gathered}
\mathrm{FGE}=\left(N_{b y, \text { red }}\right) /\left(N_{b y, \text { red }}+N_{\text {rack }}+N_{\text {ref }}\right) \\
\mathrm{FPE}=\left(N_{b y, \text { red }}+N_{\text {ref }}\right) /\left(N_{b y, \text { red }}+N_{\text {rack }}+N_{\text {ref }}\right) \\
\text { FGE }^{*}=\left(N_{b y, \text { all }}\right) /\left(N_{b y, \text { all }}+N_{\text {rack }}+N_{\text {ref }}\right) \\
\mathrm{FPE}^{*}=\left(N_{b y, \text { all }}+N_{\text {ref }}\right) /\left(N_{b y, \text { all }}+N_{\text {rack }}+N_{\text {ref }}\right)
\end{gathered}
$$

Since the experimental setup allowed the fish to easily swim back out of the bypass or back upstream through the CBR, only the first reaction for each individual fish was considered for further analyses.

To analyze and compare the behavior of the tested fish species for different hydraulic configurations, a residence coefficient $R_{c, i}$ is introduced. From the swimming paths obtained with the fish tracking software, the time spent in each sector $\left(t_{i}\right)$ and the total time spent in all sectors during the experiment 
$\left(t_{\text {tot }}\right)$ were calculated for each fish. The residence time was thus determined by dividing the time with the area of the corresponding sector for each fish $j$ in each sector $i$ and for the entire flume, i.e., the sum of all sectors, as $T_{i, j}=t_{i, j} / A_{i}$ and $T_{\mathrm{tot}, j}=t_{\mathrm{tot}, j} / A_{\mathrm{tot}}\left[\mathrm{s} / \mathrm{m}^{2}\right]$, respectively. The average residence coefficient for each hydraulic configuration was then calculated with:

$$
R_{c, i}=\frac{1}{n} \sum_{j=1}^{n} \frac{T_{i, j}}{T_{\mathrm{tot}, j}}
$$

with $i=$ sector number $(-), j=$ fish number $(-), n=$ number of active fish tested for a configuration (-). For a comparative analysis between different configurations, the sector residence coefficient was normalized by its sum $R_{c, i, \text { norm }}=R_{c, i} / \Sigma\left(R_{c, i}\right)$.

The normalized residence coefficient $R_{c, i}$,norm is thus a parameter indicating how much time a fish spent on average in a sector in comparison to the other sectors, while accounting for the sector size. If $R_{c, i}$, norm $=1$, all fish of the investigated configuration spent all their time in sector $i$, whereas if $R_{c, i, \text { norm }}=0$, none of the fish of the investigated configuration entered sector $i$.

\subsection{Statistical Analysis}

\subsubsection{Chi-Squared Test}

A chi-squared $\left(\chi^{2}\right)$ test was conducted in Matlab for each fish species separately to test the null hypothesis that there is no relation between the main parameters $U_{0}$ and $V R$, and the fish reaction at the CBR-BS. This test is thus a pairwise comparison of two independent data sets. The test value $\chi^{2}$ was calculated with a significance level of $\alpha=0.05$ with Yates's correction for small sample sizes [20]. A separate test was conducted for each fish species and for each of the four main fish reactions, i.e., all bypass passages with and without rack interaction, only bypass passages with rack interaction, rack passage or refusal.

\subsubsection{Multivariate Logistic Regression Model}

The sample size for each individual fish species was too small to set up a separate regression model for each species. To determine which of the investigated parameters significantly affected the fish reaction, the entire data set resulting from the ethohydraulic tests with the CBR-BS (Table 1) was used as well as the data set obtained by Meister [2] for the horizontal-bar rack bypass system (HBR-BS) with $\alpha=30^{\circ}$ and $s_{b}=20 \mathrm{~mm}[21,22]$, including the entity of all tested fish species. This allowed us to test the efficacy of the CBR-BS relative to the more commonly applied HBR-BS, as well as test which hydraulic parameters affected the three main fish reactions at the CBR-BS. The live-fish test results of the CBR-BS and the HBR-BS were conducted in the same time period with the same fish and the same flume setup. The BS was identical in the tests with the CBR and with the HBR.

A binomial logistic regression model was built in the statistics software $R$ (v.1.2.5033) using the generalized linear model $(\mathrm{glm})$ function of the nnet library. Three different models were set up with bypass passage (with and without rack interaction, $N_{b y, \text { all }}$ ) (yes/no), rack passage (yes/no) or refusal (yes/no) as the dependent reference variable.

To find the best fit for the present data, different logistic regression models were set up including all possible interaction terms for the main independent parameters rack type, $U_{o}$ and $V R$. The Akaike information criterion (AIC) was used to compare the models. The AIC values for the model with only the main parameters and those for the models including different interaction terms were all in the narrow range of AIC $=836-850$ (with bypass passage as the dependent variable). The simple model with all main parameters and no interaction terms was therefore chosen $(\mathrm{AIC}=847)$ to analyze the effects of the independent main parameters: rack type, $U_{o}$ and $V R$, and the secondary parameters: usage and time of day on the fish reaction. The parameter usage describes whether a fish was used once, twice or three times in a test and is thus an indicator for a possible learning or adaptation effect. 
The parameter time of day describes whether a fish was used for a test in the morning (07.00-13.00) or in the afternoon (13.00-19.00) and could be an indicator for changes in the fish's biorhythm.

A logistic regression is expressed with the odds ratio $p(X) /(1-p(X))=\exp \left(\beta_{0}+\beta_{1} \times_{1}+\ldots+\beta_{n} X_{n}\right)$, with $\beta_{\mathrm{i}}=\left(\beta_{0}, \ldots, \beta_{n}\right)=$ output coefficients of the logistic regression model. It is common to cross-compare the odds ratios, which represents the constant effect of an independent parameter $X$ on the probability that a specific outcome will occur. For the analysis of the model output, the coefficients for the odds ratio of one response category are compared to the coefficients of the reference category. All independent parameters $X_{i}$ were therefore introduced as categorical variables with the $C B R, U_{0}=0.5 \mathrm{~m} / \mathrm{s}, V R=1.2$, usage $=1$ and time of day = morning as the reference categories. This results in testing the effect of the HBR relative to the effect of the CBR, the effect of $U_{o}=0.7 \mathrm{~m} / \mathrm{s}$ relative to the effect of $U_{o}=0.5 \mathrm{~m} / \mathrm{s}$ and so on.

\subsection{Numerical Model}

To study the flow field around the curved bars, a 3D computational fluid dynamics (CFD) model of the CBR-BS in the ethohydraulic flume was set up in OpenFOAM ${ }^{\circledR}$ (v1812) based on the work of Leuch [23]. From a detailed study of different turbulence models, the shear stress transport (SST) $k-\omega$ model was found to produce the most accurate modeling results for the present application when compared with the measurement results.

The four main flow conditions used in the live-fish tests were modeled with the inflow discharge $Q_{\text {in }}$ as the inflow boundary condition. At the downstream outflow boundary, the pressure was fixed and a zero-gradient condition was defined for flow velocity. At the bypass outflow boundary, the bypass discharge $Q_{b y}$ was specified, estimated with the standard equation for weir overflow by Poleni based on water level measurements from the flume experiments.

The average mesh resolution in the domain up- and downstream of the CBR was $20 \mathrm{~mm}$. The mesh was refined around the CBR to $5 \mathrm{~mm}$ and three additional grid layers of $1 \mathrm{~mm}$ width were created around the bars (Figure 4). The simulation was conducted for $200 \mathrm{~s}$ (real time). The 3D numerical model results were averaged over the last $20 \mathrm{~s}$ of the simulation and validated with acoustic Doppler velocimetry (ADV) measurements.

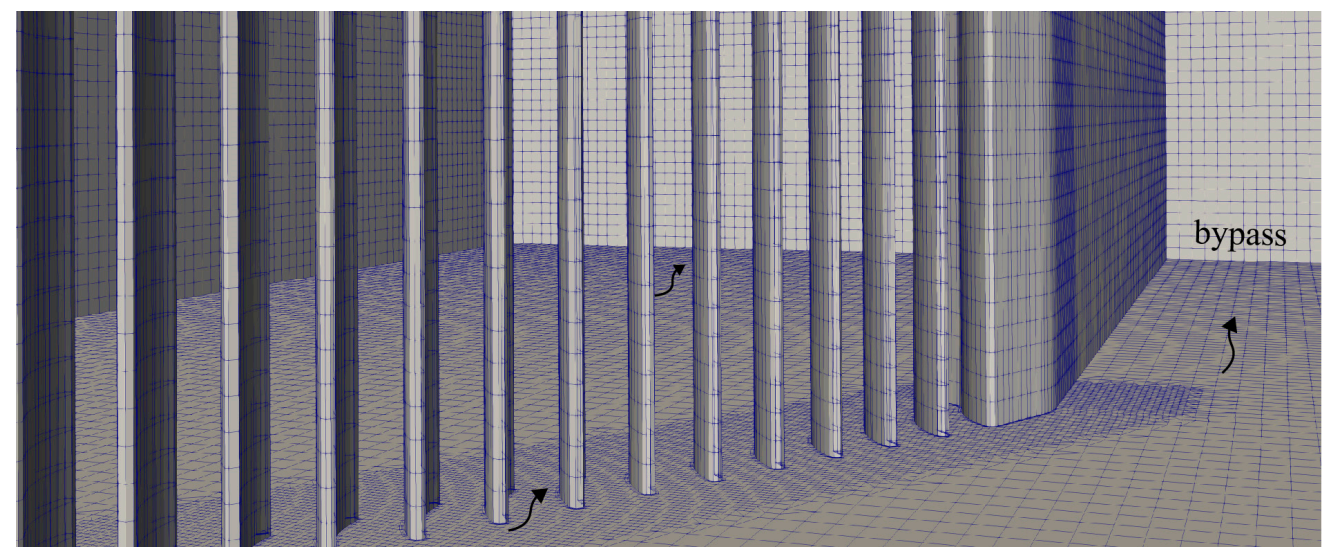

Figure 4. Detailed view of the 3D mesh at the $\mathrm{d} / \mathrm{s}$ rack end and the bypass entrance for the computational fluid dynamics (CFD) simulations of the flow fields in the ethohydraulic flume.

\section{Results}

\subsection{Hydraulics of Curved-Bar Rack Bypass Systems}

The streamwise flow velocities $U$ normalized with $U_{0}=0.7 \mathrm{~m} / \mathrm{s}$ are shown in Figure $5 \mathrm{a}, \mathrm{b}$ for $V R=1.2$ and $V R=1.4$, respectively. The normalized transverse flow velocities are shown in Figure 5c,d. A detailed view on the flow conditions at the bypass entrance is given for each flow condition. The flow fields for $U_{o}=0.5 \mathrm{~m} / \mathrm{s}$ look similar and are therefore not shown here [5]. The rack starts visibly affecting 
the flow field from approx. $x / h_{0}=-2.5$, where the low flow velocity region along the right flume wall decreases and the transversal flow velocities $V / U_{o}$ towards the bypass increase (Figure $5 c, d$ ). Expectedly, the streamwise velocities increase towards the rack and bypass, resulting in higher velocity gradients in the vicinity and inside the bypass for $V R=1.4$ compared to $V R=1.2$. The relative bypass discharges were $Q_{b y}=0.20 \cdot Q_{o}$ and $0.22 \cdot Q_{o}$ for Figure $5 a, c$ and Figure $5 b, d$, respectively.

The effect of $V R$ is visible in Figure $5 \mathrm{~d}$,d, where positive $V / U_{0}$ values extend further upstream of the rack for $V R=1.4$ compared to $V R=1.2$. At the $\mathrm{d} / \mathrm{s}$ rack end, $V / U_{0}$ increases towards the bypass and no negative $V / U_{o}$ values occur, indicating a better fish guidance efficiency for the CBR than for the similar MBR configuration. Albayrak et al. [3] reported negative $V / U_{o}$ values at the $\mathrm{d} / \mathrm{s}$ rack end of an MBR with $\alpha=30^{\circ}$, which led to an increased number of fish passing the rack at the $\mathrm{d} / \mathrm{s} \mathrm{rack}$ end. The negative $V / U_{o}$ values in that study are related to the fact that they did not regulate the bypass to achieve gradually increasing flow velocities towards the bypass. The comparison of the MBR results with the present results thus emphasizes the importance of regulating the bypass accordingly (cf. Section 4.1).

(a)

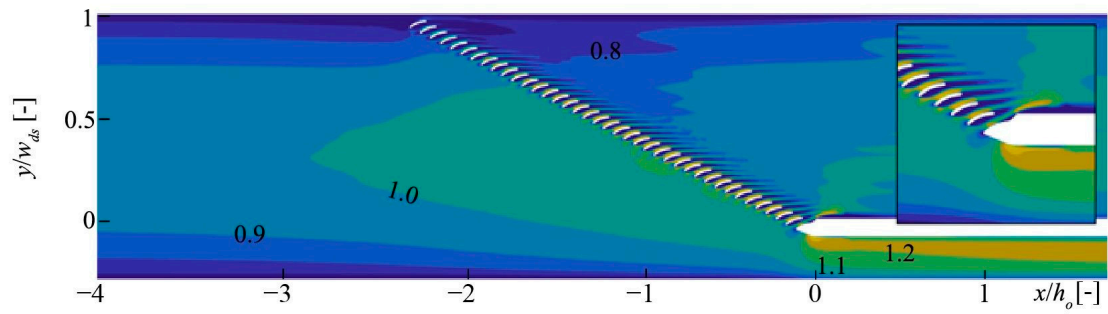

(b)

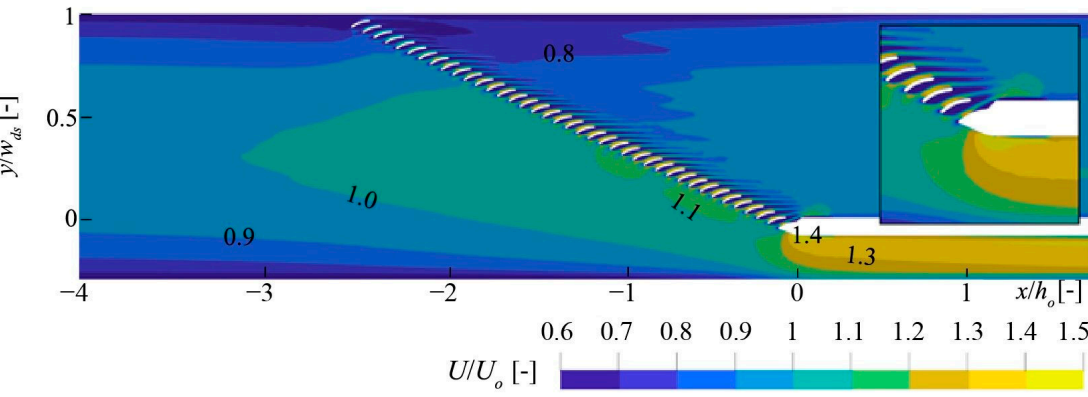

(c)

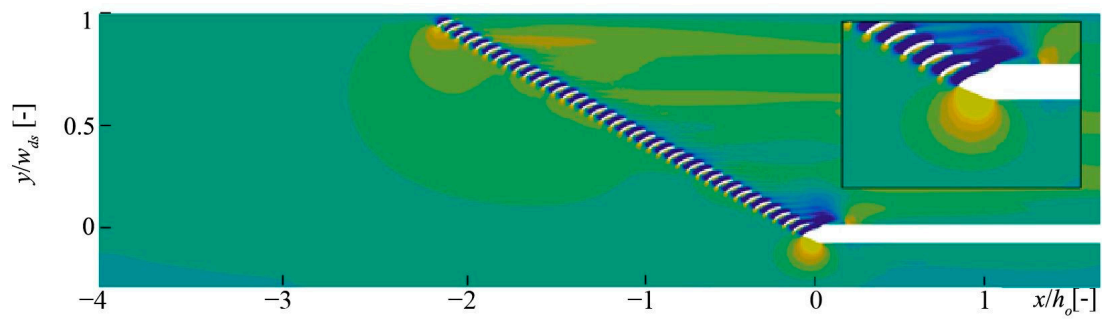

(d)

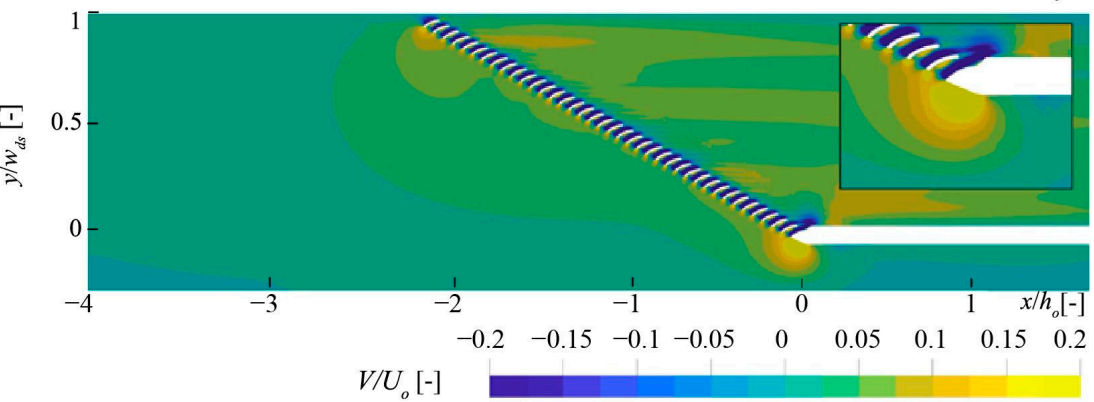

Figure 5. CFD simulation of time-averaged flow velocities normalized with $U_{0}=0.7 \mathrm{~m} / \mathrm{s}$ at $z / h_{0}=0.14$ in streamwise direction with (a) $V R=1.2$, (b) $V R=1.4$ and in transversal direction with (c) $V R=1.2$, (d) $V R=1.4$. 
The total absolute spatial velocity gradients $S V G$ between the bars located in the middle of the CBR are shown for $U_{o}=0.5 \mathrm{~m} / \mathrm{s}$ and $U_{o}=0.7 \mathrm{~m} / \mathrm{s}$ in Figure 6 a and in Figure $6 \mathrm{~b}$, respectively. The spatial pressure gradients $S P G$ in Pa/cm are shown for $U_{o}=0.5 \mathrm{~m} / \mathrm{s}$ and for $U_{o}=0.7 \mathrm{~m} / \mathrm{s}$ in Figure $6 \mathrm{c}$ and in Figure $6 \mathrm{~d}$, respectively. Since both values at this location are similar for $V R=1.2$ and 1.4, they are only shown for $V R=1.4$. SVG and SPG sharply increase at a distance of about $40 \mathrm{~mm}$ upstream of the CBR at both tested $U_{o}$ values. In contrast, $S V G$ and $S P G$ values are higher between the bars at $U_{o}=0.7 \mathrm{~m} / \mathrm{s}$ compared to $U_{o}=0.5 \mathrm{~m} / \mathrm{s}$. $S V G$ values reach up to $S V G=75 \mathrm{~s}^{-1}$ at $U_{o}=0.7 \mathrm{~m} / \mathrm{s}$ and $S V G=50 \mathrm{~s}^{-1}$ at $U_{o}=0.5 \mathrm{~m} / \mathrm{s}$. These values are much higher than the threshold of $S V G_{\mathrm{x}}>1.0-1.2 \mathrm{~s}^{-1}$ found by Haro [10] and Enders et al. [12] for triggering an avoidance reaction of Atlantic and Chinook salmon smolts, respectively. Fish are known to perceive pressure gradients with their lateral line organs [24]. However, no threshold values for SPG triggering an avoidance reaction were found in the literature.
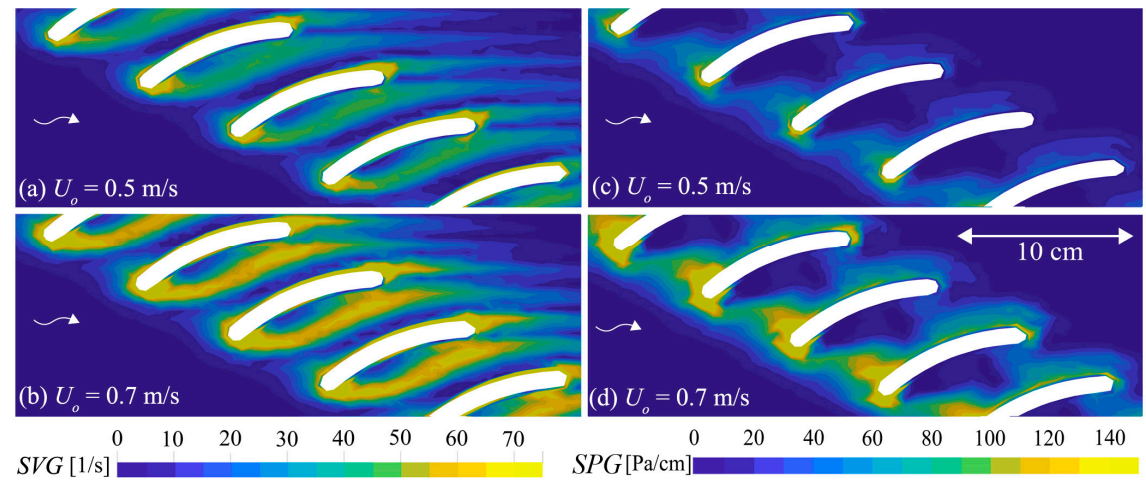

Figure 6. CFD simulation of time-averaged spatial velocity gradients $(S V G)$ and pressure gradients $(S P G)$ between the bars of the CBR $125 \mathrm{~mm}$ above the flume bed $\left(=0.14 h_{0}\right)$ for $V R=1.4$ and $(\mathbf{a}, \mathbf{c}) U_{o}=0.5 \mathrm{~m} / \mathrm{s},(\mathbf{b}, \mathbf{d}) U_{o}=0.7 \mathrm{~m} / \mathrm{s}$.

Figure 7 shows the distribution of the velocity components in the rack-parallel cross section at a distance of $50 \mathrm{~mm}$ perpendicular to the CBR with $\alpha=30^{\circ}$. The upstream $(\mathrm{u} / \mathrm{s})$ rack end and the $\mathrm{d} / \mathrm{s}$ rack end are located at $y^{\prime} / l_{R}=1$ and $y^{\prime} / l_{R}=0$, respectively. The rack normal $V_{n} / U_{0}$, and the rack parallel $V_{p} / U_{o}$ normalized velocities gradually increase along the CBR for all flow conditions from $y^{\prime} / l_{R}=1$ up to 0.5 and remain almost constant from that point until the $\mathrm{d} / \mathrm{s}$ rack end, which indicates a quasi-uniform flow distribution along the rack. The $V_{n} / U_{o}$ and $V_{p} / U_{o}$ values are slightly higher at $U_{o}=0.7 \mathrm{~m} / \mathrm{s}$ compared to $U_{o}=0.5 \mathrm{~m} / \mathrm{s}$. The fish guidance capacity FGC $=V_{p} / V_{n}$ is particularly high at the $\mathrm{u} / \mathrm{s}$ rack end $\left(y^{\prime} / l_{R}=0.9\right)$ due to the strong flow deflection towards the bypass and slightly decreases along the rack but remains above the critical value of $V_{p} / V_{n}>1$ proposed by Courret and Larinier [15] for effective fish guidance. The FGC values are almost identical for all flow conditions, but start to diverge near the bypass $\left(y^{\prime} / l_{R}=0\right)$, where the FGC is slightly higher for $V R=1.4$ compared to $V R=1.2$.

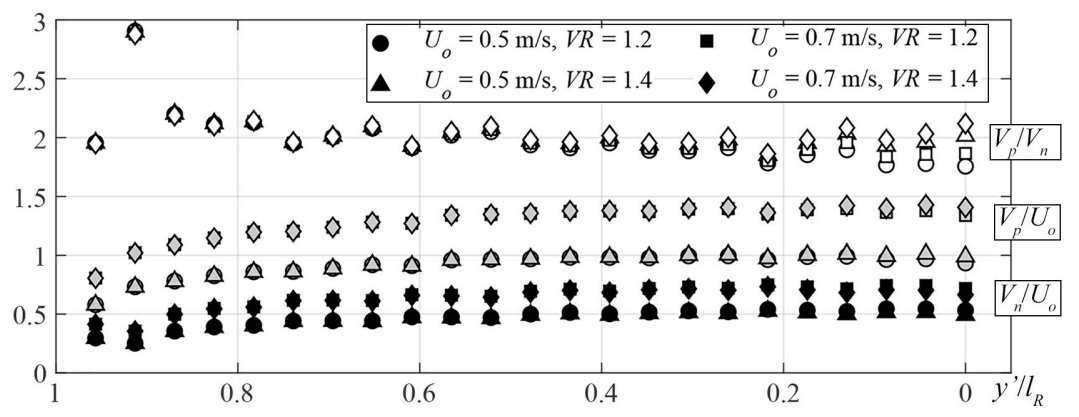

Figure 7. Velocity components fish guidance capacity (FGC) $=V_{p} / V_{n}$ (white markers), $V_{p} / U_{o}$ (gray markers) and $V_{n} / U_{0}$ (black markers) in the rack-parallel cross section at $50 \mathrm{~mm}$ upstream of the CBR for the four hydraulic conditions, simulated at $z / h_{0}=0.14$. 


\subsection{Protection and Guidance Efficiencies of Curved-Bar Rack Bypass Systems}

In this section, the fish protection and guidance efficiencies of the CBR-BS with $\alpha=30^{\circ}, \beta=45^{\circ}$, $\sigma=0.17\left(s_{b}=50 \mathrm{~mm}\right)$ and a $0.25 \mathrm{~m}$ wide full-depth open channel bypass and the general swimming behavior (qualitative observations) of the tested fish species are analyzed and discussed for each fish species separately.

\subsubsection{Spirlin}

Spirlin showed an active swimming behavior during all tests. Shortly after the test had started, they left the starting compartment and swam downstream with positive rheotaxis exploring the entire flume width. The three fish used per test showed a strong schooling behavior. Spirlin generally avoided direct contact with all structures, i.e., the flume bed and walls, or the CBR. When first approaching the CBR, the spirlin swam at a distance of approx. $15-30 \mathrm{~cm}$ to the rack and were quickly guided by the positive transverse velocities towards the bypass (Figure $5 c, d$ ). For this fish species, Sector 5 was therefore extended to a $30 \mathrm{~cm}$ wide rack-parallel area and the definition of a bypass passage with rack interaction was adjusted accordingly. In addition to the tests with four main hydraulic conditions, some spirlin were also tested without a CBR installed in the flume (no-rack configuration).

For the no-rack configuration, the distinction between FGE (= fish guidance efficiency counting only the bypass passages with rack interaction) and $\mathrm{FGE}^{*}$ ( = fish guidance efficiency counting all bypass passages) is not made. Without a CBR installed, the FGE was $14 \%$, i.e., $86 \%$ of the spirlin swam into the downstream channel, which roughly corresponds to the discharge distribution between the bypass and the downstream channel (Figure 8a, FGE = percentage of bypass passages, marked by the end of the green bar, FPE = percentage of bypass passages and refusals, marked by the end of the yellow bar). The installation of the CBR resulted in significantly higher FGEs of $63-100 \%$ (average FGE $=79 \%$ ) $\left(\chi^{2}=26.649, p<0.001\right)$, which demonstrates that the CBR functions as a mechanical behavioral barrier for spirlin. The FGE is significantly higher and the refusal rate is hence significantly lower at $U_{o}=0.5 \mathrm{~m} / \mathrm{s}$ compared to $U_{0}=0.7 \mathrm{~m} / \mathrm{s}\left(\chi^{2}=4.595, p=0.032\right)$. Furthermore, the spirlin needed more time to find and accept the bypass at $U_{o}=0.7 \mathrm{~m} / \mathrm{s}$ compared to $U_{o}=0.5 \mathrm{~m} / \mathrm{s}$, indicating a significant effect of $U_{o}$ on the FGE for spirlin. Independent of the flow conditions, no spirlin passed the rack, resulting in an FPE of $100 \%$ for all tests with the CBR. The effect of $V R$ on the FGE is not significant $\left(\chi^{2}=0.271, p=0.603\right)$.

While Figure 8a shows the protection and guidance efficiency of the entire CBR-BS with rack interaction, Figure $8 \mathrm{~b}$ also includes those fish without rack interaction and can therefore be used as an indicator for the bypass acceptance. The FGE* significantly increases to $78-100 \%$ and the absolute number of bypass passages considered in this analysis almost doubles, indicating that many fish swam into the bypass without rack interaction. The effect of $U_{0}$ on the bypass acceptance in Figure $8 \mathrm{~b}$ is significant $\left(\chi^{2}=5.023, p=0.025\right)$, while the effect of $V R$ is not significant $\left(\chi^{2}=0.060, p=0.807\right)$.

(a)

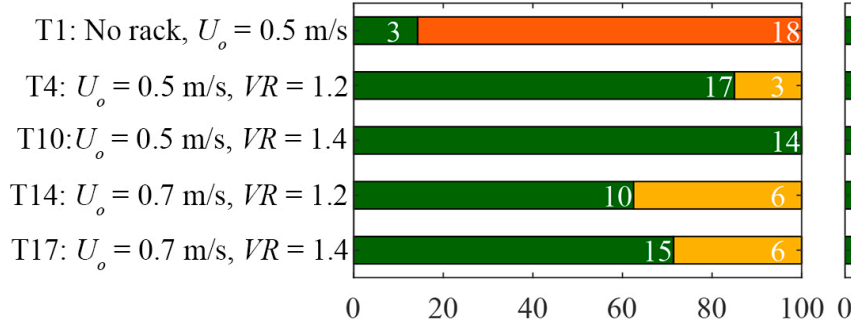

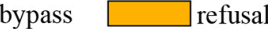

(b)

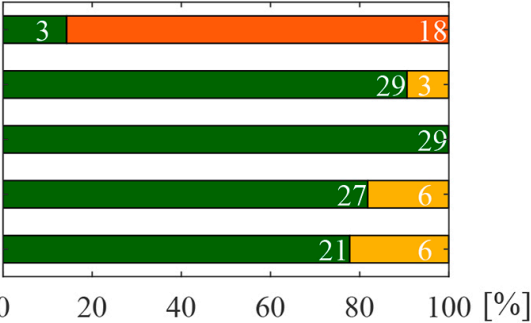

Figure 8. Rack passages, refusals and (a) bypass passages with rack interaction for $30 \mathrm{~cm}$ wide rack-parallel Sector 5 (fish guidance efficiency; FGE) and (b) all bypass passages (FGE*) for spirlin (absolute numbers of fish shown with white numbers); for T1, where no rack was installed, the fish reactions "bypass" and "rack" refer to the two channels within the flume. 


\subsubsection{Barbel}

Barbel showed a different swimming behavior compared to spirlin. Although also mostly swimming with positive rheotaxis, the barbel were more passive, spending more time in the starting compartment and preferring the low velocity regions of the flume. They showed a strong thigmotactic behavior, i.e., moving closely along the flume walls and exploring the rack with their caudal fins. Albayrak et al. [3] reported a similar swimming behavior of barbel for MBRs.

The FGEs for barbel are in a range of 54-89\% ( $\overline{\mathrm{FGE}}=76 \%$, which are slightly lower than those for spirlin (Figure 9a). Although the FGE for barbel was higher at $U_{o}=0.7 \mathrm{~m} / \mathrm{s}$ than at $U_{o}=0.5 \mathrm{~m} / \mathrm{s}$, the effect of $U_{o}$ on the bypass passages, i.e., the FGE, was not statistically significant $\left(\chi^{2}=2.727\right.$, $p=0.099$ ). Increasing $U_{0}$ caused fewer rack passages and more refusals, leading to an FPE of $100 \%$ at $U_{o}=0.7 \mathrm{~m} / \mathrm{s}$ and a significant effect on the rack passages $\left(\chi^{2}=10.417, p=0.001\right)$. The spatial velocity and pressure gradients between the bars (cf. Figure 6) and the $V_{p} / U_{o}$ values (Figure 7) are higher at $U_{o}=0.7 \mathrm{~m} / \mathrm{s}$ compared to $U_{o}=0.5 \mathrm{~m} / \mathrm{s}$, possibly leading to a stronger avoidance behavior and better guidance along the CBR, and therefore to fewer rack passages at $U_{o}=0.7 \mathrm{~m} / \mathrm{s}$ for barbel. At $U_{o}=0.5 \mathrm{~m} / \mathrm{s}$, more rack passages were observed for $V R=1.4$ compared to $V R=1.2$. The effects of $V R$ on the fish reaction or the bypass acceptance were not significant, however $\left(\chi^{2}=0.102, p=0.750\right)$.

The FGE* and thus the bypass acceptance for barbel is $74-91 \%$ (Figure $9 b$ ). Since barbel preferred to swim or drift along the right flume wall in front of the bypass, many fish entered the bypass without rack interaction. The barbel often swam to the right flume wall shortly after leaving the starting compartment. Since the flow is unaffected by the CBR this far upstream of the rack, the reason for this preference is unclear.

(a)

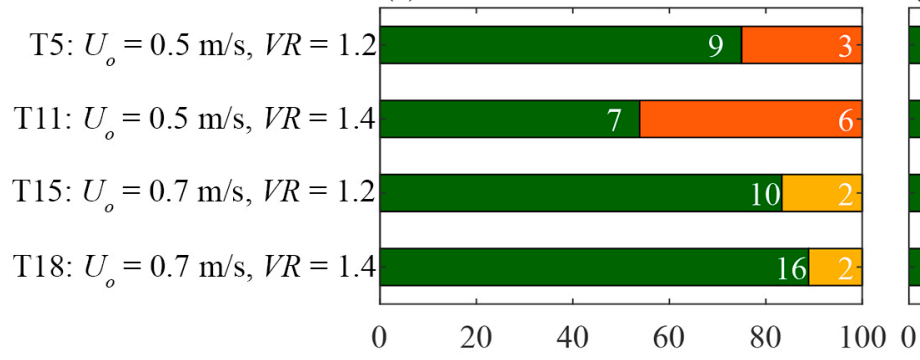

bypass $\square$ refusal

(b)

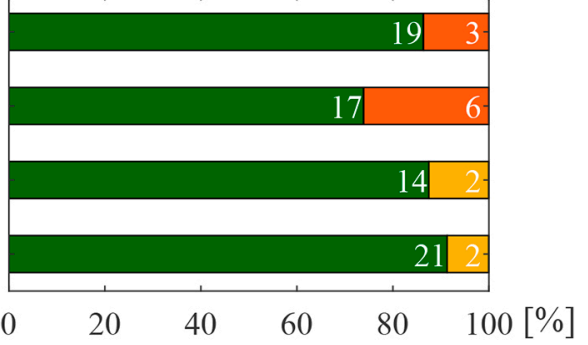

Figure 9. Rack passages, refusals and (a) bypass passages with rack interaction (FGE) and (b) all bypass passages (FGE*) for barbel (absolute numbers of fish shown with white numbers).

\subsubsection{Nase}

Nase showed a similar swimming behavior to spirlin. They left the starting compartment quickly and actively swam downstream with positive rheotaxis using the entire flume width. Similar to spirlin, nase did not touch the rack, but seemed to perceive the CBR as an obstacle due to the increased velocity and pressure gradients upstream of the rack (cf. Figure 6). When approaching the CBR, nase searched actively in the $15 \mathrm{~cm}$ wide rack-parallel area. All tested nase interacted with the rack, i.e., swam into Sector 5, and no refusals occurred, thus FGE equals FPE, FGE* and FPE* in Figure 10 for both tested flow conditions. Since some of the nase hesitated to use the bypass and hence ended up passing the rack at $V R=1.2$, the bypass flow was reduced to $V R=1.1$. The flow fields were not measured or simulated for $V R=1.1$, however. Although the number of fish tested for the latter was small and the effect of $V R$ on the FGE is not significant $\left(\chi^{2}=0.886, p=0.347\right)$, visual observations indicated that nase hesitated less at the bypass and accepted it quickly at $V R=1.1$. 


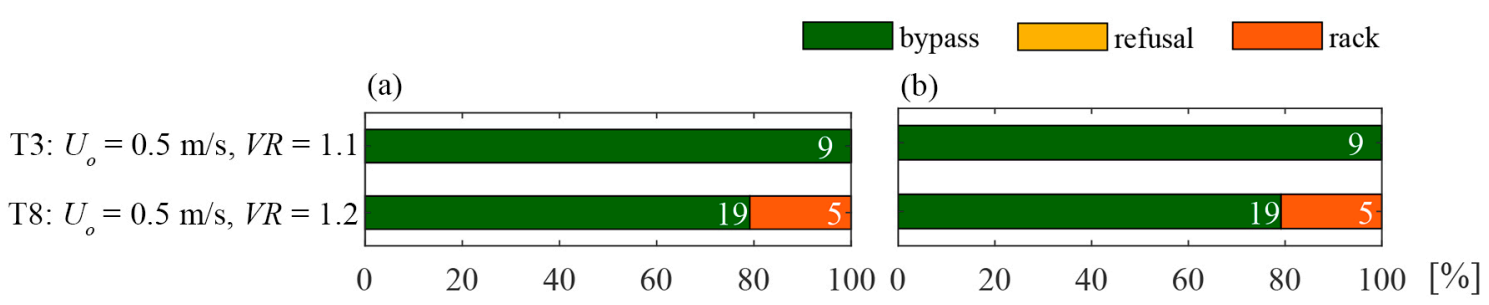

Figure 10. Rack passages and (a) bypass passages with rack interaction (FGE) and (b) all bypass passages $\left(\mathrm{FGE}^{*}\right.$ ) for nase (absolute numbers of fish shown with white numbers).

\subsubsection{European Eel}

The swimming behavior of the European eel was completely different compared to the other tested fish species and similar to the one described in Silva et al. [25] and Schwevers and Adam [26]. In most of the tests, the eels approached the CBR with negative rheotaxis, collided with the rack and passed it without hesitation. Eels generally reacted insensitively to the hydrodynamic cues created by the CBR, which led to a low FGE and FPE of $27 \%$ (Figure 11a). Since the tested eels preferred to swim along the wall and were thus often guided to the bypass without rack interaction, the FGE $^{*}$ and the FPE $^{*}$ were $43 \%$, and were hence higher than the FGE and the FPE (Figure 11b). Note that the total number of experiments conducted with eels is small due to limited catch rate of these fish at the time of the live-fish tests.

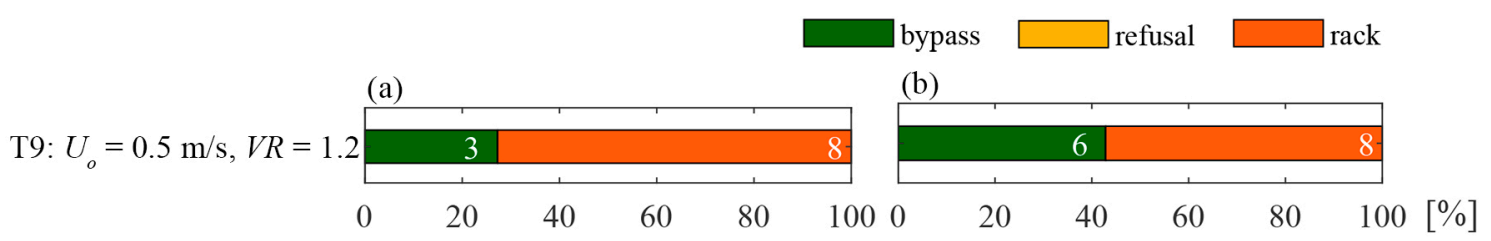

Figure 11. Rack passages and (a) bypass passages with rack interaction (FGE) and (b) all bypass passages (FGE*) for the European eel (absolute numbers of fish shown with white numbers).

\subsubsection{Atlantic Salmon Parr}

The salmon parr left the starting compartment quickly and actively moved downstream with positive rheotaxis. The three fish of each test often swam together in a loose school. Salmon parr generally swam close to the CBR with a distance of a few centimeters. The fish repeatedly moved away from the rack, approached it again and were thereby guided to the bypass. Sometimes they interacted with the CBR and explored the spaces between two bars with their caudal fins. The visual observations indicated that the fish reacted with burst swimming against the flow between the bars. The flow detachment at the upstream bar tips led to a distinct shear layer and high velocity and pressure gradients (cf. Figure 6), which were most likely perceived and avoided by these fish. These results therefore confirm the findings of Haro [10] that $S V G_{x}$ values much higher than $1.0 \mathrm{~s}^{-1}$ lead to a hesitation reaction for Atlantic salmon parr.

Due to the high effort of catching Atlantic salmon parr in Switzerland, these fish were only tested at $U_{o}=0.5 \mathrm{~m} / \mathrm{s}$. The FGE was high at $88 \%$ and $79 \%$ for $V R=1.2$ and $V R=1.4$, respectively (Figure 12a). The effect of $V R$ on the FGE is not significant $\left(\chi^{2}=0.238, p=0.625\right)$. More rack passages were observed for $V R=1.4$ compared to $V R=1.2$, although this difference is not significant $\left(\chi^{2}=0.855, p=0.355\right)$. Due to the close interaction of the fish with the CBR, the values for FGE* and FPE* are only marginally higher (Figure 12b). Although the salmon parr were not tested at $U_{0}=0.7 \mathrm{~m} / \mathrm{s}$, the FGE and FPE are expected to be similarly high or even higher at $U_{0}=0.7 \mathrm{~m} / \mathrm{s}$ compared to $U_{0}=0.5 \mathrm{~m} / \mathrm{s}$ because of the higher velocity and pressure gradients between the bars occurring at $U_{0}=0.7 \mathrm{~m} / \mathrm{s}$. 
(a)

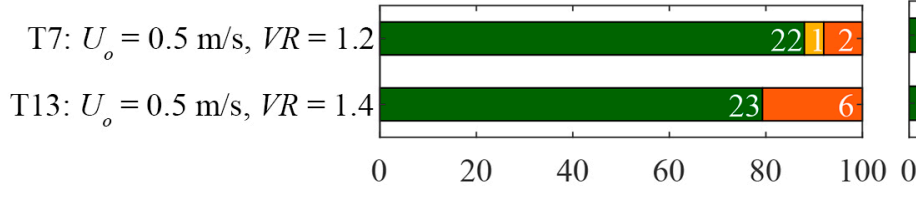

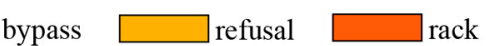

(b)

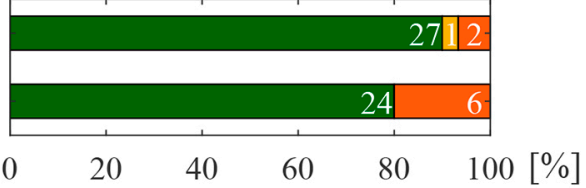

Figure 12. Rack passages, refusals and (a) bypass passages with rack interaction (FGE) and (b) all bypass passages $\left(\mathrm{FGE}^{*}\right.$ ) for salmon parr (absolute numbers of fish shown with white numbers).

\subsubsection{Brown Trout}

Brown trout were the most inactive among all tested fish species, i.e., they left the starting compartment only after several minutes, and $38 \%$ of the fish did not exit it at all. Once trout had left the starting compartment, however, they swam actively with mostly positive rheotaxis, showing only a weak schooling behavior. In the majority of the tests, the trout explored the water flow between the bars with their caudal fins, often reacting with swimming upstream for a few fish lengths, with rheotaxis changes along the rack as described by Anderson et al. [27] or with a rack passage.

The FGE for brown trout was low at $30 \%$ and $43 \%$ for $U_{o}=0.5 \mathrm{~m} / \mathrm{s}$ and $0.7 \mathrm{~m} / \mathrm{s}$, respectively, and significantly higher at $79 \%$ for $U_{0}=0.3 \mathrm{~m} / \mathrm{s}\left(\chi^{2}=4.361, p=0.037\right.$, Figure 13a). Compared to the FGE, the FPE was higher at 59-79\%. The FPE was higher for $V R=1.2$ compared to $V R=1.4$ at each approach flow velocity. This effect was not statistically significant, however $\left(\chi^{2}=0.676, p=0.411\right)$. Due to the close interaction with the CBR, the values for FGE* and FPE* are only marginally higher (Figure 13b).

(a)

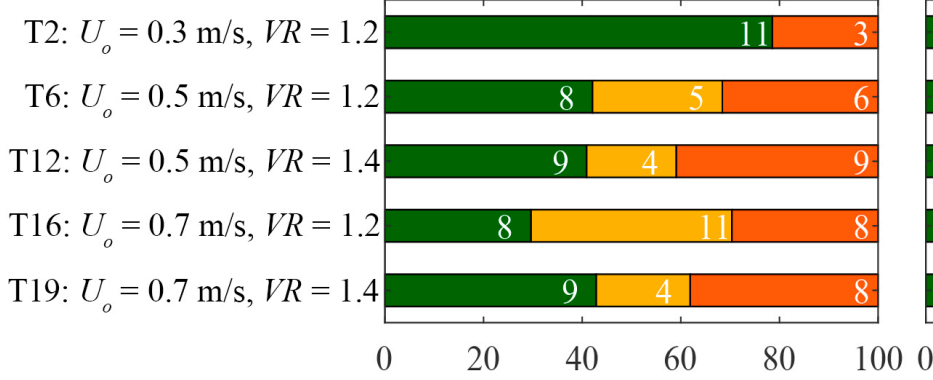

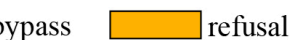

(b)

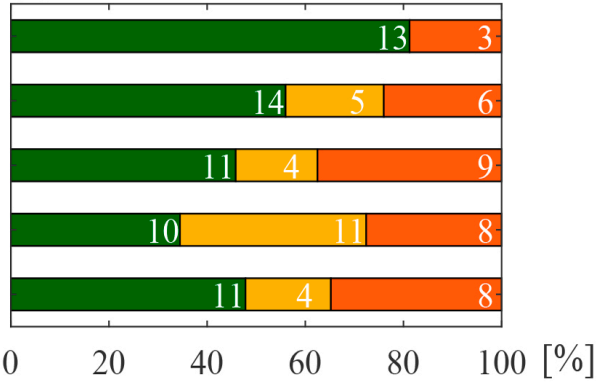

Figure 13. Rack passages, refusals and (a) bypass passages with rack interaction (FGE) and (b) all bypass passages $\left(\mathrm{FGE}^{*}\right)$ for brown trout (absolute numbers of fish shown with white numbers).

\subsubsection{Interspecies Comparison of Occurrence of Fish in Time and Space}

The flow condition with $U_{0}=0.5 \mathrm{~m} / \mathrm{s}$ and $V R=1.2$ was tested with all six fish species. The computed

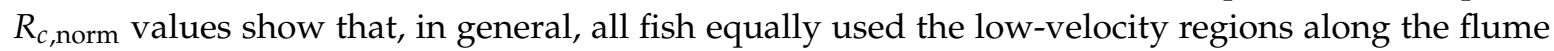
walls (Sec1 and Sec2), with some exceptions (e.g., nase) (Figure 14). Barbel and spirlin particularly preferred the glass wall on the right flume side leading into the bypass (Sec2, Sec7) to the mortar wall on the left flume side (Sec1). Among the tested fish species, spirlin spent the least amount of time in Sector 5, which is in line with the result that no rack passage was observed for this fish species. For the flow condition shown in Figure 14, nase spent the most time, i.e., almost 50\% of their time, near the CBR. This behavior is related to their sensitive reaction to $V R=1.2$, which led to exploratory movements to find an alternative route along the rack. Although nase spent a lot of time exploring the rack-parallel area, few rack passages were observed (cf. Figure 10), which indicates a strong behavioral avoidance of these fish of the CBR. 


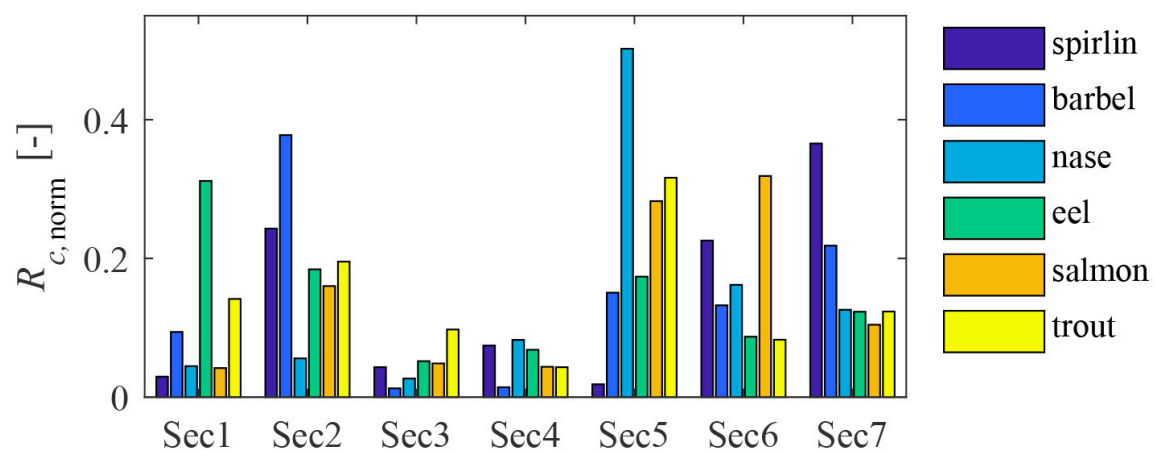

Figure 14. Normalized residence coefficient $R_{c, \text { norm }}$ for the flow condition with $U_{o}=0.5 \mathrm{~m} / \mathrm{s}$ and $V R=1.2$ for the different tested fish species.

Although brown trout and Atlantic salmon parr spent a similar amount of time in rack-parallel Sector 5 , considerably more rack passages were observed for brown trout. This result indicates that the CBR did not function well as a behavioral barrier for the tested life stage of brown trout for the flow condition underlying Figure 14.

\subsection{Average Fish Protection and Guidance Efficiencies}

Figure 15 shows the average, minimum and maximum fish protection and guidance efficiencies considering only the bypass passages with rack interaction (FGE, FPE) and considering all bypass passages $\left(\mathrm{FGE}^{*}, \mathrm{FPE}^{*}\right)$ resulting from the live-fish tests. The values are computed by taking the weighted average efficiencies over all tested flow conditions for each fish species. No minimum or maximum values are shown for eel, since they were only tested with one flow condition. The average FGEs and FPEs are higher than $75 \%$ and $80 \%$, respectively, for spirlin, barbel, nase and salmon parr, while they are below $75 \%$ and $80 \%$, respectively, for brown trout and even below $50 \%$ for European eel. The FPEs are only slightly higher than the FGEs for nase, eel and salmon parr, indicating that these fish species rarely refused the CBR-BS but swam either into the bypass or through the CBR. In contrast, the average FPE is considerably higher than the average FGE for spirlin, barbel and brown trout, because these fish refused the CBR-BS and swam back upstream more often if they did not swim through the CBR or into the bypass. The average $\mathrm{FGE}^{*}$ and $\mathrm{FPE}^{*}$ are only slightly higher than the average FGE and FPE, which indicate that considering the rack interaction does not greatly affect the resulting protection and guidance efficiencies for most of the tested fish species.

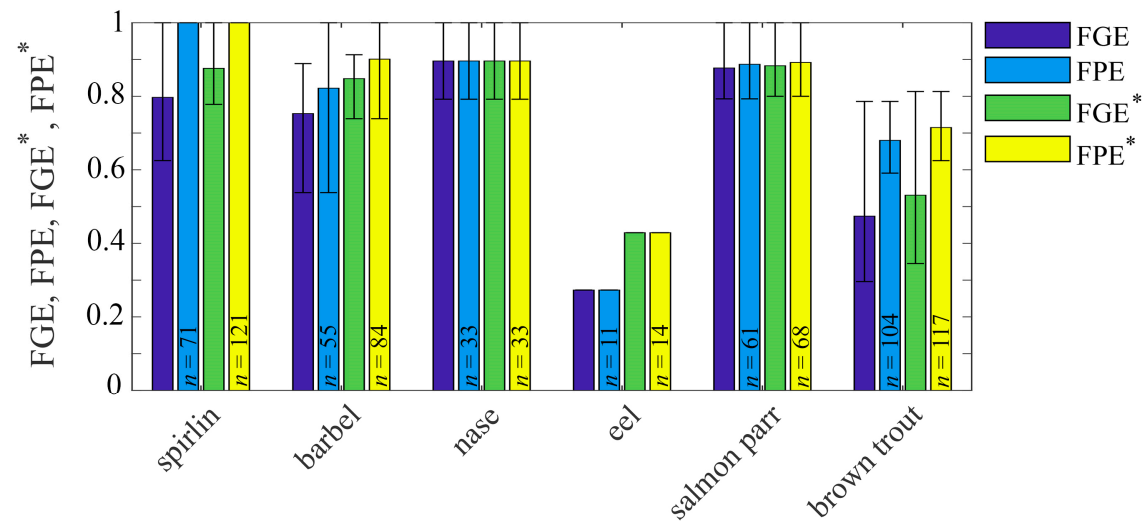

Figure 15. Average fish guidance and protection efficiencies considering only the bypass passages with rack interaction (FGE, fish protection efficiency; FPE) and considering all bypass passages (FGE*, $\mathrm{FPE}^{*}$ ); the minimum and maximum values are indicated with horizontal lines except for eel. 


\subsection{Logistic Regression Model}

Three separate binary logistic regression models incorporating all tested fish species were set up to investigate the extent to which various factors affect the likelihood of each dependent response variable: (i) bypass passage with and without rack interaction, (ii) rack passage or (iii) refusal. The results can therefore be interpreted as a fish species community metric. Table 2 lists the output of the three models. The reference configuration to which all outputs of the model are compared is the CBR, $U_{0}=0.5 \mathrm{~m} / \mathrm{s}$, $V R=1.2$, usage $=1$, time of day = morning. As an example, for the reference configuration, the resulting $\beta$ value for the intercept indicates that the odds of a bypass passage were $\exp \left(\beta_{0}\right)=\exp (1.299)=3.666$ times higher than those for the other reactions (rack passage and refusal). The probability of a bypass passage can thus be calculated to $P_{0}=3.666 /(1+3.666)=0.79$ compared to the significantly lower probability of an alternative reaction (rack passage or refusal) $P_{1}=1 /(1+3.666)=0.21$.

The rack type has the most significant effect on the bypass and the rack passages among all modeled parameters (Table 2). Changing the rack from the CBR to the horizontal bar rack (HBR), while maintaining the reference values for the other parameters $\left(U_{0}, V R\right.$, usage, time of day $)$, significantly decreases the odds of a bypass passage and a refusal, but significantly increases the odds of a rack passage.

In the tested range, the approach flow velocity $U_{o}$ did not have a significant effect on the bypass passages, i.e., the FGE of the CBR-BS, but it significantly affected the refusal and the rack passage rates (Table 2). Increasing $U_{o}$ from $0.5 \mathrm{~m} / \mathrm{s}$ to $0.7 \mathrm{~m} / \mathrm{s}$ thus significantly increased the number of refusals and significantly decreased the number of rack passages. This result suggests that the higher SVG and SPG values (cf. Figure 6) and increased rack-parallel velocity components $V_{p} / U_{o}$ (cf. Figure 7 ) at $U_{o}=0.7 \mathrm{~m} / \mathrm{s}$ compared to $U_{o}=0.5 \mathrm{~m} / \mathrm{s}$ lead to an increased behavioral barrier effect. However, the higher value of $U_{o}=0.7 \mathrm{~m} / \mathrm{s}$ was only tested for three out of the six fish species, i.e., spirlin, barbel and brown trout, with different effects on the behavior for the individual species (cf. Section 3.2).

The regression model further shows that in the tested range, the higher $V R$ significantly decreases the odds of a bypass passage and significantly increases the odds of a rack passage, although the $\chi^{2}$ tests yielded no significance of $V R$ for each individual fish species. The logistic regression model integrates all fish species, however, resulting in a much larger sample size. This result coincides with the observation that many fish quickly accepted the bypass for $V R=1.2$, but showed hesitation or avoidance for $V R=1.4$, taking more time to accept the bypass. $V R$ did not have a significant effect on the number of refusals (Table 2).

Table 2. Output of the three binary logistic regression models (M1-M3) with bypass passage, rack passage or refusal as the dependent variable: regression coefficients $\beta_{i}$ comparing the odds of each outcome to the standard configuration with the standard errors given in parentheses, $N=$ number of fish included in the model, BIC = Bayesian information criterion, AIC = Akaike information criterion; significance levels are denoted with ${ }^{*} p<0.05,{ }^{* *} p<0.01$, ${ }^{* * *} p<0.001$ and without asterisk for $p>0.05$.

\begin{tabular}{cccc}
\hline & M1: Bypass & M2: Rack & M3: Refusal \\
\hline Intercept & $1.299^{* * *}$ & $-2.262^{* * *}$ & $-1.300^{* *}$ \\
& $(0.281)$ & $(0.317)$ & $(0.472)$ \\
Rack type: HBR & $-0.553^{* * *}$ & $0.834^{* * *}$ & $-0.682^{*}$ \\
& $(0.168)$ & $(0.187)$ & $(0.291)$ \\
$U_{0}: 0.7 \mathrm{~m} / \mathrm{s}$ & -0.158 & $-0.477^{*}$ & $1.386^{* * *}$ \\
& $(0.176)$ & $(0.201)$ & $(0.285)$ \\
VR: 1.4 & $-0.327^{*}$ & $0.380^{*}$ & 0.145 \\
& $(0.165)$ & $(0.182)$ & $(0.277)$ \\
Usage & -0.077 & $0.315^{* * *}$ & $-0.831^{* * *}$ \\
& $(0.083)$ & $(0.091)$ & $(0.175)$ \\
Time of day & $-0.539^{* *}$ & 0.223 & $1.085^{* * * *}$ \\
$N$ & $(0.170)$ & $(0.189)$ & $(0.283)$ \\
Log-likelihood & 639 & 639 & 639 \\
BIC & -417.687 & -361.048 & -179.417 \\
AIC & 874.134 & 760.855 & 397.595 \\
& 847.370 & 734.100 & 370.840 \\
\hline
\end{tabular}


For model M1, the odds for the secondary variable usage are nearly 1 , which indicates that this variable has a negligible effect on the bypass passages, indicating no fish learning or habituation effects. Despite this, using the fish a second or third time for a test significantly increased the rack passages and decreased the refusal rate, which indicates a habituation effect to the CBR.

The time of day a fish was used in the experiment shows a significant effect on the bypass passages and the refusals. A fish that was used in the afternoon was less likely to pass the bypass and more likely to refuse the CBR-BS compared to fish that were used in the morning.

Since the secondary parameters usage and time of day were only introduced to improve the model fit of the logistic regression model, they are neglected for the interpretation of the main parameters. In conclusion, the reference configuration, i.e., the CBR, $U_{0}=0.5 \mathrm{~m} / \mathrm{s}$ and $V R=1.2$, leads to the highest probability $\left(P_{0}=79 \%\right)$ of a bypass passage, i.e., the highest interspecies FGE, over all ethohydraulic tests conducted in this study and in Meister [2]. The HBR, $U_{0}=0.7 \mathrm{~m} / \mathrm{s}$ and $V R=1.4$, leads to the lowest interspecies probability of a bypass passage $\left(P_{0: H B R: U o: V R}=57 \%\right)$. The authors refer to Beck [5] for a more detailed explanation and interpretation of the model outputs.

\section{Discussion}

The findings of this study demonstrate that the CBR functions well as a mechanical behavioral barrier for spirlin, barbel, nase and Atlantic salmon parr, with high fish protection and guidance efficiencies $(>75 \%)$, whereas it had a lower or no behavioral effect for brown trout and European eel, respectively. The study further demonstrates that the swimming behavior of the tested salmonid, cyprinid and anguillid fish species are subject to large interspecies variations. Moreover, the average total length of the tested fish was different for each fish species (cf. Table 1), which further increases the behavioral variability.

Barbel, salmon parr and brown trout all explored the flow fields near the CBR and between the bars with their caudal fins and often stayed in direct contact with the rack. These fish-rack interactions did not lead to a high rack passage rate for the barbel and the salmon parr. Conversely, many brown trout passed the rack, indicating less or no avoidance reaction to the high velocity and pressure gradients in the vicinity and between the bars of the CBR.

European eel showed a completely different behavior overall, often approaching the CBR with a negative rheotaxis and passing the rack without reacting to any hydrodynamic cues. The total number of experiments conducted with European eel was small due to limited catch rate of these fish at the time of the live-fish tests. Since the eel did not react to the mechanical or behavioral barrier effects of the CBR, increasing the number of tested individuals might not change the resulting FGE and FPE. Nevertheless, more tests with the European eel are recommended for a larger range of hydraulic conditions. The FGE of the European eel might be increased with a bottom overlay [3,17] or smaller clear bar spacings. Meister et al. [28] equipped the CBR with a low-voltage electric field, which significantly increased the protection and guidance of these fish.

Nase reacted sensitively to high velocity gradients and showed an increased avoidance behavior to $V R=1.2$ at the bypass, which led to exploratory movements to find an alternative route along the rack. Nevertheless, the number of rack passages for nase was small. Nase and spirlin generally showed a similar swimming behavior. Both fish species actively explored the flume and were quickly guided to the bypass. At $V R=1.2$, the spirlin quickly accepted the bypass, whereas the nase hesitated more often, which led to more rack passages in the case of the nase compared to spirlin. The mean total length of the nase was $7.2 \mathrm{~cm}$ while it was $10 \mathrm{~cm}$ for the spirlin. It is therefore possible that the stronger hesitation reaction of the nase compared to the spirlin is related to their smaller total length and lower swimming capacities.

The FGE of brown trout was highest at $U_{o}=0.3 \mathrm{~m} / \mathrm{s}$. This result is surprising, since the spatial velocity and pressure gradients between the bars and hence the behavioral barrier effect of the CBR decrease with decreasing $U_{0}$. Since the flow field was not measured or simulated for $U_{0}=0.3 \mathrm{~m} / \mathrm{s}$, however, it remains unclear why the FGE was much higher for this flow condition. 
Although the parameters significantly affecting the fish behavior were identified, the overall number of tested fish was low. However, the fish were caught during multiple fishing events for each species and relatively large size ranges and thus different age classes were tested for most species, hence the likelihood to have drawn unequally different behavioral types should be small.

Other parameters such as temperature or lighting conditions might further affect the fish behavior. Ibbotson et al. [29] found that Atlantic salmon smolts predominantly migrated during the night, when the water temperature was below $12{ }^{\circ} \mathrm{C}$. For higher water temperatures, however, there was no significant difference between diurnal and nocturnal migration rates. Similar findings were reported by Fraser et al. [30] for Atlantic salmon parr. Since the water temperature in the present live-fish experiments was between $12-16^{\circ} \mathrm{C}$, it was assumed that the salmon parr were day active. However, there is little knowledge about the diel movement behavior of cyprinid species and more research is needed. The normal behavior of the different fish species in the laboratory flume of the present study suggests that the light intensity did not stress the fish. Nonetheless, it cannot be ruled out that certain species and size classes were more or less active due to the broad daylight conditions in the flume.

\subsection{Comparison to Other Fish Guidance Structures}

Flügel et al. [31], Kriewitz [18] and Albayrak et al. [3] conducted similar ethohydraulic tests with modified bar racks (MBRs) and louvers, combined with a $20 \mathrm{~cm}$ wide full-depth open channel bypass in 2014 in the same laboratory flume as for the present study. In their data analysis, they did not distinguish between bypass passages with and without rack interaction, therefore only the total fish guidance efficiency including all bypass passages with and without interaction (FGE*) and the respective total fish protection efficiency $\left(\mathrm{FPE}^{*}\right.$ ) can be compared between their results and the present study. Table 3 lists the FGE* and the FPE ${ }^{*}$ for the CBR with $\alpha=30^{\circ}$ and a clear bar spacing of $s_{b}=50 \mathrm{~mm}$ (this study), the horizontal-bar rack (HBR) with $\alpha=30^{\circ}$ and $s_{b}=20 \mathrm{~mm}$ with otherwise identical conditions [2], two MBR configurations with $\alpha=15^{\circ}, 30^{\circ}$ and $s_{b}=50 \mathrm{~mm}$ and the louver with $\alpha=15^{\circ}$ and $s_{b}=50 \mathrm{~mm}[3,18]$. The results are given for the tested flow conditions. During the tests with the MBRs and the louver, the bypass was not regulated, so VR was different for each MBR and louver, and for different $U_{0}$ values.

For spirlin, nase and salmon parr, the FGE* and the FPE* are considerably higher with the CBR compared to the HBR, which indicates that the behavioral barrier effect of the widely spaced CBR $\left(s_{b}=50 \mathrm{~mm}\right)$ was higher than the physical barrier effect of the more narrowly spaced HBR $\left(s_{b}=20 \mathrm{~mm}\right)$ for these fish species and life stages. Note that none of the nase with $T L_{\text {mean }}=7.2 \mathrm{~cm}$ was guided to the bypass with the HBR, while the FGE was $79-100 \%$ with the CBR. The FGE* of the CBR and the HBR are similar for barbel and brown trout. However, trout are not sufficiently guided or protected by neither the CBR nor the HBR in these laboratory studies. For European eel, the FGE* and the FPE* are both substantially higher for the HBR compared to the CBR. These results indicate that the CBR could overall lead to higher average fish protection and guidance, minimizing operational issues compared to the HBR.

The MBRs and the louver were partly tested with the same fish species $[3,18]$. Table 3 indicates that the FGE* and the FPE* are similar for the MBRs and the CBR for spirlin, barbel and brown trout, whereas they are considerably lower with the louver because of the unfavorable flow field, i.e., high $V_{n} / U_{o}$ values at the $\mathrm{d} / \mathrm{s}$ rack end [3]. The MBR with $\alpha=15^{\circ}$ led to a much higher FGE* and FPE* for European eel and brown trout than the CBR with $\alpha=30^{\circ}$. No tests with eel and trout were conducted with the MBR with $\alpha=30^{\circ}$, however. The higher FGE* and FPE* are therefore possibly a result of the lower rack angle or the larger body size of brown trout tested with the MBR $\left(T L_{\text {mean }}=19.5 \mathrm{~cm}\right)$. It is expected that the CBR with $\alpha=15^{\circ}$ may lead to a similarly high FGE for brown trout and European eel as the MBR with the same rack angle. Furthermore, Kriewitz [18] and Albayrak et al. [3] reported slightly higher FGE* and FPE* for most tested fish species with a bottom overlay (Bo) with $h_{B o}=0.11 \cdot h_{0}$ (Table 3). In the present study, no overlays were tested in the ethohydraulic experiments with the CBR. Since in the laboratory tests most fish swam along the flume bed, the $\mathrm{FGE}^{*}$ and $\mathrm{FPE}^{*}$ are expected to 
increase with a bottom overlay. However, the swimming depth of fish in prototype conditions can vary greatly and the efficiency of overlays in the field still needs to be proven. For the louver, the FGE and $\mathrm{FPE}^{*}$ were considerably higher at $U_{0}=0.3 \mathrm{~m} / \mathrm{s}$ compared to $U_{0}=0.6 \mathrm{~m} / \mathrm{s}$ for spirlin and barbel, whereas no clear effect of $U_{o}$ on the FGE* was observed for the MBRs. The FPE* was slightly higher at $U_{o}=0.6 \mathrm{~m} / \mathrm{s}$ compared to $U_{o}=0.3 \mathrm{~m} / \mathrm{s}$ for the MBR with $\alpha=30^{\circ}$. This result matches well with the higher FPE $^{*}$ of the CBR for barbel at $U_{o}=0.7 \mathrm{~m} / \mathrm{s}$ compared to $U_{o}=0.5 \mathrm{~m} / \mathrm{s}$ (cf. Section 3.2.2). The CBR with $\alpha=30^{\circ}$ and $\beta=45^{\circ}$ and the MBR with $\alpha=15^{\circ}$ and $\beta=45^{\circ}$ both resulted in $\mathrm{FPE}^{*}=100 \%$ for spirlin, independent of $U_{o}$.

Table 3. FGE* and FPE* for different fish guidance structures (FGSs) and different fish species tested in the same ethohydraulic flume at VAW of ETH Zurich, data for MBRs and louver taken from $[3,18]$ (Bo $=$ bottom overlay with $h_{B o}=0.11 \cdot h_{0}$ ), data for the HBR from [2].

\begin{tabular}{|c|c|c|c|c|c|c|c|}
\hline \multirow[b]{2}{*}{$\operatorname{FGS}(\alpha, \beta)$} & \multirow[b]{2}{*}{$U_{o}(\mathrm{~m} / \mathrm{s})$} & \multicolumn{6}{|c|}{ FGE $^{*}(\%)$} \\
\hline & & Spirlin & Barbel & Trout & Eel & Nase & Salmon Parr \\
\hline $\operatorname{CBR}\left(30^{\circ}, 45^{\circ}\right)$ & $0.5 / 0.7$ & $78-100$ & 74-91 & $34-81$ & 43 & 79-100 & 80-90 \\
\hline $\operatorname{MBR}\left(30^{\circ}, 45^{\circ}\right)$ & $0.3 / 0.6$ & $75 / 75$ & $86 / 100$ & - & - & - & - \\
\hline MBR and Bo $\left(30^{\circ}, 45^{\circ}\right)$ & 0.6 & 76 & 100 & 96 & 95 & - & - \\
\hline \multirow[t]{2}{*}{ Louver $\left(15^{\circ}, 90^{\circ}\right)$} & $0.3 / 0.6$ & $81 / 10$ & $79 / 65$ & - & - & - & - \\
\hline & & \multicolumn{6}{|c|}{ FPE $^{*}(\%)$} \\
\hline $\operatorname{CBR}\left(30^{\circ}, 45^{\circ}\right)$ & $0.5 / 0.7$ & 100 & $74-100$ & $63-81$ & 43 & 79-100 & 80-93 \\
\hline $\operatorname{HBR}\left(30^{\circ}, 45^{\circ}\right)$ & $0.5 / 0.7$ & $82-100$ & 85-96 & $46-68$ & $88-100$ & $0-5$ & $29-46$ \\
\hline MBR and Bo $\left(15^{\circ}, 45^{\circ}\right)$ & 0.6 & - & 100 & 100 & 95 & - & - \\
\hline Louver $\left(15^{\circ}, 90^{\circ}\right)$ & $0.3 / 0.6$ & $90 / 75$ & $79 / 65$ & - & - & - & - \\
\hline
\end{tabular}

The results listed in Table 3 confirm the findings by Enders et al. [12] and indicate that not only salmonids but also cyprinid fish species react sensitively to high $S V G$ values and avoid sudden velocity changes. The CBRs and MBRs, which lead to milder velocity gradients along the rack, resulted in substantially higher FGE* as compared to louvers. Enders et al. [12] found that Chinook salmon smolts started showing avoidance reactions for spatial velocity gradients $S V G \approx 1.0 \ldots 1.2 \mathrm{~s}^{-1}$ and proposed that this threshold is associated with the energetically optimum swimming speed of fish, which correspond to about 1 body length per second. Similar threshold values for salmonids were found by Haro [10] and Goodwin et al. [32]. No definite threshold values are reported for potamodromous fish species, however, neither for velocity nor pressure gradients.

Overall, these results demonstrate that the CBR functioned as a mechanical behavioral barrier for spirlin, barbel, nase and salmon parr with high FGE and FPE, whereas it had low or no behavioral effect for brown trout and the European eel for the tested parameter range, life stages and fish total lengths (cf. Section 3.3, Figure 15). Smaller bar spacings, lower rack angles, a bottom overlay or the electrification of the rack might be approaches to achieve higher FGE and FPE for these fish species.

\subsection{Engineering Application}

In this study, only one CBR configuration with $\alpha=30^{\circ}, \beta=45^{\circ}, s_{b}=50 \mathrm{~mm}$ was tested, since this configuration creates low head losses and a symmetric downstream flow field $[8,9]$. MBRs that were tested with different bar angles $\beta$ led to significantly higher FGEs with $\beta=45^{\circ}$ than with $\beta=90^{\circ}[3,18]$. Similar trends are expected for the CBR since the velocity gradients upstream of the CBR are more gradual and the maximum velocities at the $\mathrm{d} / \mathrm{s}$ rack end are decreased for $\beta=45^{\circ}$ compared to $\beta=90^{\circ}$ [9] . The application of CBRs with $\beta=45^{\circ}$ is therefore recommended. 
The MBR with $\alpha=15^{\circ}$ led to a much higher FGE* and FPE* for European eel and brown trout than the CBR with $\alpha=30^{\circ}$ (cf. Table 3). The higher FGE* and FPE* of these two fish species are therefore possibly a result of the lower rack angle. EPRI [17] showed high FGE for milder rack angles, i.e., $\alpha=15^{\circ}$, for the tested North American fish species. Similar or even higher FGEs for CBRs than for louvers and MBRs can be expected for $\alpha<30^{\circ}$ because of the improved flow fields [9] and are therefore recommended to improve the FGE and FPE for European eel and brown trout.

In addition to $s_{b}=50 \mathrm{~mm}$, Kriewitz [18] conducted live-fish tests with barbel and spirlin at MBRs and louvers with larger bar spacings of $s_{b}=110 \mathrm{~mm}$ and reported that the FGE significantly decreased for $s_{b}=110 \mathrm{~mm}$ compared to $s_{b}=50 \mathrm{~mm}$. EPRI [17] investigated angled-bar racks with $\alpha=45^{\circ}$, and with $s_{b}=25 \mathrm{~mm}$ and $50 \mathrm{~mm}$. At $U_{o}=0.6 \mathrm{~m} / \mathrm{s}$, the FGEs were considerably higher for $s_{b}=25 \mathrm{~mm}$ for the riverine species (bass, walleye, shiner and catfish), whereas $s_{b}$ did not have an effect on the FGE of American eel for this rack angle. It is expected that both physical and behavioral barrier effects of the CBR decrease with increasing $s_{b}$. To ensure a high degree of fish guidance, clear bar spacings of $s_{b} \leq 50 \mathrm{~mm}$ are therefore recommended.

Although overlays were not tested with fish in the present study, it is expected that fish guidance increases similarly as seen for louvers and MBRs with overlays $[3,18]$. The parallel velocity components $V_{p}$ increase, while the normal velocity components $V_{n}$ decrease in front of the overlays, locally reducing the risk of fish entrainment through the CBR. Additional overlay blockage at CBRs slightly deteriorates the downstream flow field and causes spiral flow but only marginally increases the head losses [8,9]. Ebel [1] proposes a minimum height for top and bottom overlay of $h_{T o}=1.0 \mathrm{~m}$ and $h_{B o}=0.5 \mathrm{~m}$, respectively. Based on the results of Beck [5] and Beck et al. [8,9], a total maximum overlay height of $h_{v}=(0.20-0.30) \cdot h_{0}$ is recommended for a high fish guidance efficiency and the mitigation of operational issues, i.e., driftwood clogging and sediment transport, by considering site-specific geometrical and operational conditions.

According to the logistic regression model including all fish species and two different rack types (CBR and HBR), the approach flow velocity $U_{o}$ did not have a significant effect on the number of bypass passages, i.e., the fish guidance efficiency, of the CBR-BS in the tested range. However, the number of refusals significantly increased, and the rack passages significantly decreased, resulting in a higher fish protection efficiency for $U_{0}=0.7 \mathrm{~m} / \mathrm{s}$ compared to $U_{o}=0.5 \mathrm{~m} / \mathrm{s}$. Furthermore, the fish spent more time near the CBR and took more time to find and accept the bypass at $U_{0}=0.7 \mathrm{~m} / \mathrm{s}$. The lower approach flow velocity $U_{o}=0.3 \mathrm{~m} / \mathrm{s}$ was only tested with brown trout and led to a significant increase in the FGE for these fish. The live-fish tests were conducted with a CBR with $\alpha=30^{\circ}$ and a maximum $U_{o}$ of $0.7 \mathrm{~m} / \mathrm{s}$, resulting in $V_{n} \leq 0.5 \mathrm{~m} / \mathrm{s}$ (Figure 7). The smallest fish tested at this velocity, i.e., the spirlin with a minimum body length of $8.4 \mathrm{~cm}$, navigated along the flume and in front of the CBR in a controlled manner and without obvious exhaustion for the total duration of the test of $45 \mathrm{~min}$. The impingement of a fish on the CBR was not observed in any of the conducted tests. The USBR [13] recommends maximum approach flow velocities to louvers of $U_{0}=0.30-0.61 \mathrm{~m} / \mathrm{s}$ for weak and $U_{0}=0.83-1.37 \mathrm{~m} / \mathrm{s}$ for strong swimmers. Based on the results of this study, it is recommended to select the rack angle $\alpha$ to comply with the criteria $V_{n} \leq v_{\text {sustained }}$ with $v_{\text {sustained }}=$ sustained swimming speed of fish proposed by Ebel [1] and Turnpenny and O'Keeffe [16] to enable fish of all sizes to react to the hydrodynamic cues of the mechanical behavioral barrier and avoid exhaustion. This recommendation leads to lower rack angles $\alpha$ for higher approach flow velocities $U_{0}$, since $V_{n} \approx U_{0} \cdot \sin (\alpha)$.

The ratio of the bypass entrance velocity to the approach flow velocity $V R=U_{b y, i n} / U_{o}$ had a significant effect on the fish guidance efficiency. The total number of bypass passages significantly decreased, while the number of rack passages increased for $V R=1.4$ compared to $V R=1.2$ (cf. Table 2). Some fish species like spirlin or nase reacted more sensitively to $V R$ than others like barbel, brown trout, salmon parr or European eel. Although most available practice guidelines recommend a bypass discharge as a percentage of the approach flow discharge [13], the presented results indicate that $V R$ is the decisive parameter for an efficient bypass design, which is quickly accepted by fish. Ebel [1] recommends $V R=1.0-2.0$ for all fish species, while USBR [13] proposes $V R=1.1-1.5$ for 
American fish species. To protect and guide fish of all species, life stages and sizes, $V R=1.1-1.2$ is recommended according to the findings of this study.

\section{Conclusions}

The overarching goal of this research study was to improve the sustainable and efficient use of hydropower by providing a technical solution for the safe downstream fish movement at run-of-river hydropower plants and water intakes with a minimal impact on hydropower production and operation. To this end, an innovative curved-bar rack bypass system (CBR-BS) was developed and its hydraulic performance and fish protection and guidance efficiencies were assessed by means of ethohydraulic experiments and numerical modeling. Finally, the results of the live-fish tests were compared with those of a similar study by Meister [2] with a horizontal-bar rack bypass system (HBR-BS). The key findings of this study are:

- The velocity and pressure gradients between the bars of the CBR and up to $\sim 40 \mathrm{~mm}$ upstream of the rack are particularly high, thereby triggering an avoidance reaction of the downstream moving fish. The live-fish test results confirm the behavioral barrier effect of the CBR on most of the tested fish species in the tested range of fish total lengths and life stages. European eel and, to some extent, brown trout were an exception, because they reacted considerably less to the hydrodynamic cues of the CBR-BS than the other fish species.

- In the tested range $(0.5-0.7 \mathrm{~m} / \mathrm{s})$, the approach flow velocity $U_{o}$ did not have a significant effect on the fish guidance efficiency. It significantly affected the refusal and the rack passage rates, however. Increasing $U_{o}$ from $0.5-0.7 \mathrm{~m} / \mathrm{s}$ significantly increased the number of refusals and significantly decreased the number of rack passages. This result suggests that the higher velocity and pressure gradients near and between the bars of the CBR at $U_{o}=0.7 \mathrm{~m} / \mathrm{s}$ compared to $U_{o}=0.5 \mathrm{~m} / \mathrm{s}$ lead to an increased behavioral barrier effect.

- Increasing the ratio of bypass entrance to approach flow velocity $V R$ from 1.2 to 1.4 significantly decreased the number of bypass passages and significantly increased the number of rack passages. This result underlines the importance of a regulated bypass design.

- The CBR functioned as a mechanical behavioral barrier for spirlin, barbel, nase and Atlantic salmon parr with high fish protection and guidance efficiencies $(>75 \%)$ for the tested fish sizes and life stages, whereas it had low or no behavioral effect for brown trout and European eel, respectively.

- The fish protection and guidance efficiencies for nase, spirlin and salmon parr were significantly higher for the CBR with larger clear bar spacings $\left(s_{b}=50 \mathrm{~mm}\right)$ than for the horizontal-bar rack (HBR) with smaller clear bar spacings $\left(s_{b}=20 \mathrm{~mm}\right.$ ), whereas it was similar for barbel and brown trout. This result indicates that the predominant behavioral barrier effect of the CBR can lead to a higher fish protection and guidance than the predominant physical barrier effect of the HBR.

- The live-fish tests allowed for a detailed observation, which increased the understanding of the fish swimming behavior of a range of European freshwater fish species at the CBR-BS under laboratory conditions.

Given the highly reduced head losses, improved up- and downstream hydraulic conditions and high fish protection and guidance efficiencies, CBRs present a promising solution for the safe downstream fish movement for certain fish species at small-to-large hydropower plants and water intakes with minimum economic and operational impacts. Although parameters affecting the behavior of the entire tested species community were identified, the findings of this study emphasize that there is a large interspecies variability of fish swimming behavior, which must be accounted for when planning a fish protection measure. We recommend testing a pilot CBR at a hydropower plant and evaluating its effectiveness with a thorough monitoring study.

Author Contributions: Conceptualization, C.B., I.A., J.M., A.P. and R.M.B.; methodology, C.B., I.A., J.M., A.P., O.M.S., D.F.V. and R.M.B.; software, C.B., J.M., O.M.S., C.L. and D.F.V.; validation, C.B., J.M., O.M.S., D.F.V. and C.L.; formal analysis, C.B.; investigation, C.B. and J.M.; resources, I.A. and R.M.B.; data curation, C.B.; 
writing—original draft preparation, C.B.; writing—review and editing, C.B., I.A., J.M., A.P., O.M.S., C.L., D.F.V. and R.M.B.; visualization, C.B.; supervision, I.A., D.F.V. and R.M.B.; project administration, C.B., I.A., A.P. and R.M.B.; funding acquisition, I.A. and R.M.B. All authors have read and agreed to the published version of the manuscript.

Funding: This project received funding from the European Union's Horizon 2020 research and innovation program under grant agreement no. 727830, FIThydro (Fishfriendly Innovative Technologies for hydropower). The authors would further like to thank the Swiss State Secretariat for Education, Research and Innovation (SERI) for their support.

Acknowledgments: The authors would like to acknowledge the expert support by Nils Schölzel (fish biologist, FishConsulting $\mathrm{GmbH}$ ) during the electrofishing, the fish handling and the experimental setup.

Conflicts of Interest: The authors declare no conflict of interest.

\section{Abbreviations}

$\begin{array}{ll}\text { BS } & \text { Bypass system } \\ \text { CBR } & \text { Curved-bar rack } \\ \text { CFD } & \text { Computational fluid dynamics } \\ \text { FGC } & \text { Fish guidance capacity } \\ \text { FGS } & \text { Fish guidance structure } \\ \text { FGE } & \text { Fish guidance efficiency } \\ \text { FPE } & \text { Fish protection efficiency } \\ \text { HBR } & \text { Horizontal-bar rack } \\ \text { HPP } & \text { Hydropower plant } \\ \text { MBR } & \text { Modified angled-bar rack } \\ \text { SPG } & \text { Spatial pressure gradient } \\ \text { SVG } & \text { Spatial velocity gradient } \\ \text { VR } & \text { Velocity ratio }\left(U_{b y, i n} / U_{o}\right)\end{array}$

\section{References}

1. Ebel, G. Fischschutz und Fischabstieg an Wasserkraftanlagen-Handbuch Rechen-und Bypasssysteme. Ingenieurbiologische Grundlagen, Modellierung und Prognose, Bemessung und Gestaltung; Mitteilungen aus dem Büro für Gewässerökologie und Fischereibiologie Dr. Ebel, Band 4; Büro für Gewässerökologie und Fischereibiologie: Halle, Germany, 2016.

2. Meister, J. Fish Protection at Hydropower Plants with Horizontal Bar Rack Bypass Systems; VAW-Mitteilung 258; Boes, R.M., Ed.; VAW, ETH Zurich: Zurich, Switzerland, 2020; in press.

3. Albayrak, I.; Boes, R.M.; Kriewitz-Byun, C.R.; Peter, A.; Tullis, B.P. Fish guidance structures: Hydraulic performance and fish guidance efficiencies. J. Ecohydraul. 2020. [CrossRef]

4. Albayrak, I.; Kriewitz, C.R.; Hager, W.; Boes, R.M. An experimental investigation on louvres and angled bar racks. J. Hydraul. Res. 2018, 56, 59-75. [CrossRef]

5. Beck, C. Fish Protection and Fish Guidance at Water Intakes Using Innovative Curved-Bar Rack Bypass Systems; VAW-Mitteilung 257; Boes, R.M., Ed.; VAW, ETH Zurich: Zurich, Switzerland, 2020; Available online: https://vaw.ethz.ch/das-institut/publikationen/vaw-mitteilungen/2020-2029.html (accessed on 30 October 2020).

6. Bates, D.W.; Vinsonhaler, R. Use of louvers for guiding fish. Trans. Am. Fish. Soc. 1957, 86, 38-57. [CrossRef]

7. EPRI. Review of Downstream Fish Passage and Protection Technology Evaluations and Effectiveness; Technical Report 111517; Electric Power Research Institute: Palo Alto, CA, USA, 1998.

8. Beck, C.; Albayrak, I.; Meister, J.; Boes, R.M. Hydraulic performance of fish guidance structures with curved bars-Part 1: Head loss assessment. J. Hydraul. Res. 2020, 58, 807-818. [CrossRef]

9. Beck, C.; Albayrak, I.; Meister, J.; Boes, R.M. Hydraulic performance of fish guidance structures with curved bars-Part 2: Flow fields. J. Hydraul. Res. 2020, 58, 819-830. [CrossRef]

10. Haro, A.; Odeh, M.; Noreika, J.; Castro-Santos, T. Effect of water acceleration on downstream migratory behavior and passage of Atlantic salmon smolts and juvenile American shad at surface bypasses. Trans. Am. Fish. Soc. 1998, 127, 118-127. [CrossRef]

11. Ducharme, L.J.A. Application of louver deflectors for guiding Atlantic salmon. J. Fish. Res. Board Can. 1972, 29, 1397-1404. [CrossRef] 
12. Enders, E.C.; Gessel, M.H.; Anderson, J.J.; Williams, J.G. Effects of decelarating and accelerating flows on juvenile salmonid behavior. Trans. Am. Fish. Soc. 2012, 141, 357-364. [CrossRef]

13. USBR. Fish Protection at Water Diversions-A Guide for Planning and Designing Fish Exclusion Facilities; Technical Report; U.S. Department of the Interior, Bureau of Reclamation: Denver, CO, USA, 2006.

14. Ruggles, C.P.; Ryan, P. An investigation of louvers as a method of guiding juvenile Pacific salmon. Can. Fish Cult. 1964, 33, 1-68.

15. Courret, D.; Larinier, M. Guide pour la Conception de Prises D'eau 'Ichtyocompatibles' pour les Petites Centrales Hydroélectriques (Guide for the Design of Fish-Friendly Intakes for Small Hydropower Plants); Agence de l'Environnement et de la Maîtrise de l'Energie (ADEME): Paris, France, 2008. (In French)

16. Turnpenny, A.W.H.; O'Keeffe, N. Screening for Intake and Outfalls: A Best Practice Guide; Technical Report SC030231; Environment Agency: Bristol, UK, 2005.

17. EPRI; DML. Evaluation of Angled Bar Racks and Louvers for Guiding Fish at Water Intakes; Technical Report 1005193; Electric Power Research Institute and Dominion Millstone Laboratories: Palo Alto, CA, USA; Waterford, CT, USA, 2001.

18. Kriewitz, C.R. Leitrechen an Fischabstiegsanlagen: Hydraulik und Fischbiologische Effizienz (Guidance Screens at Fish Protection Facilities: Hydraulics and Fish-Biological Efficiency); VAW-Mitteilung 230; Boes, R.M., Ed.; VAW, ETH Zurich: Zurich, Switzerland, 2015. (In German)

19. Harby, A.; Charmosson, J.; Boavida, I.; Pinheiro, A.N.; Godinho, F.; Tuthan, J.; Albayrak, I.; Detert, M.; Boes, R.M.; Schneider, M. Tools for fish behaviour assessment. In Deliverable 3.2 Horizon 2020 Research Programme Fishfriendly Innovative Technologies for Hydropower; European Commission: Brussels, Belgium, 2019; Available online: https:/ec.europa.eu/inea/en/horizon-2020/projects/h2020-energy/hydropower/fithydro (accessed on 30 October 2020).

20. Yates, F. Contingency tables involving small numbers and the chi-square test. R. Stats Soc. 1934, 1, $217-235$.

21. Meister, J.; Fuchs, H.; Beck, C.; Albayrak, I.; Boes, R.M. Head Losses of Horizontal Bar Racks as Fish Guidance Structures. Water 2020, 12, 475. [CrossRef]

22. Meister, J.; Fuchs, H.; Beck, C.; Albayrak, I.; Boes, R.M. Velocity Fields at Horizontal Bar Racks as Fish Guidance Structures. Water 2020, 12, 280. [CrossRef]

23. Leuch, C. Numerical Modelling of Fish Guidance Structures. Master's Thesis, VAW, ETH Zurich, Zurich, Switzerland, 2019, unpublished.

24. Ristroph, L.; Liao, J.C.; Zhang, J. Lateral Line Layout Correlates with the Differential Hydrodynamic Pressure on Swimming Fish. Phys. Rev. Lett. 2015, 114, 018102. [CrossRef] [PubMed]

25. Silva, A.T.; Katopodis, C.; Tachie, M.F.; Santos, J.M.; Ferreira, M.T. Downstream swimming behaviour of catadromous and potamodromous fish over spillways. Riv. Res. Appl. 2016, 32, 935-945. [CrossRef]

26. Schwevers, U.; Adam, B. Fish Protection Technologies and Fish Ways for Downstream Migration; Springer: Berlin/Heidelberg, Germany, 2019.

27. Anderson, W.G.; Shepherd, D.; Katopodis, C.; McKinley, R.S.; Rajaratnam, N. Laboratory and Field Testing of a Louver Array for the Guidance of Juvenile Rainbow Trout; Technical Report; Applied Biometrics Inc.: Waterloo, ON, Canada; Department of Civil Engineering, University of Alberta: Edmonton, AB, Canada, 1998.

28. Meister, J.; Beck, C.; Roth, A.; Fuchs, H.; Albayrak, I.; Selz, O.; Boes, R.M. EthoMoSt, Etho-hydraulische Modellversuche an Elektrifizierten Fischleitrechen (Etho-Hydraulic Model Study on Electrified Fish Guidance Structures); Technical Report SI/501758-01; Swiss Federal Office of Energy: Bern, Switzerland, 2020. (In German)

29. Ibbotson, A.T.; Beaumont, W.R.C.; Pinder, A.; Welton, S.; Ladie, M. Diel migration patterns of Atlantic salmon smolts with particular reference to the absence of crepuscular migration. Ecol. Freshw. Fish 2006, 15, 544-551. [CrossRef]

30. Fraser, N.H.C.; Metcalfe, N.B.; Thorpe, J.E. Temperature-dependent switch between diurnal and nocturnal foraging in salmon. Proc. R. Soc. Lond. Ser. B 1993, 252, 135-139.

31. Flügel, D.; Bös, T.; Peter, A. Forschungsprojekt: Massnahmen zur Gewährleistung eines Schonenden Fischabstiegs an Grösseren Mitteleuropäischen Flusskraftwerken-Ethohydraulische Untersuchungen zum Fischabstieg Entlang eines Vertikalen, Schräg Ausgerichteten Fischleitrechens (Investigation on Downstream Fish Migration along Vertical, Angled Fish Guidance Screens_Ethohydraulic Investigations in a Laboratory Flume); Technical Report; Swiss Federal Institute of Aquatic Science and Technology (Eawag): Dübendorf, Switzerland, 2015. (In German) 
32. Goodwin, R.A.; Nestler, J.M.; Anderson, J.J.; Weber, L.J. A new tool to forecast fish movement and passage. Hydro Rev. 2007, 26, 58-71.

Publisher's Note: MDPI stays neutral with regard to jurisdictional claims in published maps and institutional affiliations.

(C) 2020 by the authors. Licensee MDPI, Basel, Switzerland. This article is an open access article distributed under the terms and conditions of the Creative Commons Attribution (CC BY) license (http://creativecommons.org/licenses/by/4.0/). 